\title{
An Arrayed Genome-Wide Perturbation Screen Identifies the Ribonucleoprotein hnRNP K As
}

\section{Rate-Limiting for Prion Propagation}

Merve Avar¹, Daniel Heinzer*1, Alana M. Thackray², Yingjun Liư ${ }^{1}$, Marian Hruska-Plochan ${ }^{3}$, Stefano Sellitto ${ }^{1}$, Elke Schaper ${ }^{1}$, Daniel P. Pease ${ }^{1}$, Jiang-An Yin ${ }^{1}$, Asvin K.K. Lakkarajuํ, Marc Emmenegger ${ }^{1}$, Marco Losa1, Andra Chincisan¹, Simone Hornemann¹, Magdalini Polymenidou ${ }^{3}$, Raymond Bujdoso², Adriano Aguzzi" ${ }^{1 \#}$

Author affiliations:

1: Institute of Neuropathology, University of Zurich, $\mathrm{CH}-8091$ Zurich, Switzerland

2: University of Cambridge, Department of Veterinary Medicine, Madingley Road, Cambridge, CB3 OES, UK

3: Department of Quantitative Biomedicine, University of Zurich, $\mathrm{CH}-8057$, Switzerland

*: equal contribution

\#: to whom correspondence should be addressed at: adriano.aguzzi@usz.ch 


\section{Abstract}

A defining characteristic of mammalian prions is their capacity for self-sustained propagation. Theoretical considerations and experimental evidence suggest that prion propagation is modulated by cell-autonomous and non-autonomous modifiers. Using a novel quantitative phospholipase protection assay (QUIPPER) for high-throughput prion measurements, we performed an arrayed genome-wide RNA interference (RNAi) screen aimed at detecting modifiers of prion propagation. We exposed prioninfected cells in high-density microplates to $35^{\prime} 364$ ternary pools of $52^{\prime} 746$ siRNAs targeting $17^{\prime} 582$ genes representing the mouse protein-coding transcriptome. We identified 1191 modulators of prion propagation. While 1151 of these modified the expression of both the pathological prion protein, PrPsc, and its cellular counterpart $\mathrm{PrP}^{\mathrm{C}}, 40$ genes affected selectively $\mathrm{PrP}^{\mathrm{Sc}}$. Of the latter, 20 genes augmented prion production when suppressed. A prominent limiter of prion propagation was the heterogeneous nuclear ribonucleoprotein Hnrnpk. Psammaplysene A (PSA), which binds Hnrnpk, reduced prion levels in cultured cells and protected them from cytotoxicity. PSA also reduced prion levels in infected cerebellar organotypic slices and alleviated locomotor deficits in prion-infected Drosophila melanogaster expressing ovine $\mathrm{PrP}^{\mathrm{C}}$. Hence, genome-wide QUIPPER-based perturbations can discover actionable cellular pathways involved in prion propagation. Finally, the unexpected identification of a prioncontrolling ribonucleoprotein suggests a role for RNA in the generation of infectious prions. 


\section{Introduction}

The life cycle of mammalian prions entails the misfolding and aggregation of the cellular protein $\operatorname{PrPC}$ and its incorporation into a nucleated higher-order isoform called PrPsc (Aguzzi and Calella, 2009). Once the $\mathrm{PrP}^{\mathrm{Sc}}$ aggregates reach a critical size, they break and elongate again by recruiting additional monomers (Knowles et al., 2009).This cyclic sequence of events is the basis for the increase in prion infectivity (Nuvolone et al., 2009). However, it is still unknown whether this process occurs autonomously akin to crystal growth, or if it necessitates auxiliary cofactors (Deleault et al., 2012a; Deleault et al., 2012b). The latter is suggested by the observation that propagation of prions in a cell-free system is inefficient and necessitates extreme conditions such as cyclic high-energy sonication, shaking, or partial chemical denaturation (Atarashi et al., 2011; Saborio et al., 2001). In contrast, infection of animals or cultured cells with prions can yield titer increases by several orders of magnitude under physiological conditions (Klöhn et al., 2003; Prusiner et al., 1982). This suggests that living systems contain important cofactors that enable prion propagation, e.g., by lowering the thresholds of rate-limiting reactions.

How could one possibly identify such cofactors? In the case of other neurodegenerative diseases, crucial insights were derived from human genetics. The study of families afflicted by inherited forms of Alzheimer's and Parkinson's disease have yielded a plethora of genes encoding proteins directly linked to the offending aggregates (Jansen et al., 2019; Nalls et al., 2019; van Rheenen et al., 2016). However, this approach has not been as successful in the case of prion diseases, partly because of their rarity which precludes large genome-wide association studies (Lloyd et al., 2013). As a result, the only modifiers robustly associated with predisposition to prion diseases are genetic polymorphisms within the PrPC-encoding PRNP gene itself (Jones et al., 2020; Mead et al., 2009; Mead et al., 2012; SanchezJuan et al., 2014).

A possible approach to this conundrum consists of investigating candidate genes which may be inferred from existing reports or from their role in phenomena pertinent to prion propagation. For example, transcription factors involved in PRNP mRNA expression (Bellingham et al., 2009; Dery et al., 2013; Rybner et al., 2002; Vincent et al., 2009), or proteins involved in its degradation (Parkyn et al., 2008; Shyu et al., 2002; Vincent et al., 2009), may represent such candidates. However, this approach has major limitations. Any potential candidates, in order to be identified as such, must have been described previously in similar contexts. Consequently, any fundamentally novel mechanisms cannot be discovered because they would not exist as priors. 
Forward genetic screens, in which each protein-coding gene is being modified and hits are identified by their effect on the phenotype of interest, represent a less biased and more inclusive approach with the potential of yielding wholly unpredicted hits. Moreover, the identification of relationships between hits, e.g., because they fall within a single pathway, or because they encode individual components of a single physical complex, can fortify the confidence in the validity of the results. In the past, such screens have been most effectively performed in unicellular organisms that undergo a haploid phase, such as yeast (Giorgini et al., 2005; Outeiro and Lindquist, 2003). However, more recent technologies such as RNA interference (RNAi) and CRISPR have enabled the deployment of forward genetic screens in diploid mammalian cells (Heinzer et al., 2021; Kampmann, 2018; Mohr et al., 2010).

In this work, we have used arrayed RNAi to interrogate all genes of the mouse genome for their influence on prion propagation. We have discovered 40 such genes. 20 of these were found to reduce prion propagation when suppressed, but 20 genes enhanced prion propagation when silenced. Some of these modifiers fell within pathways expected to control prion propagation (Marbiah et al., 2014). However, others were entirely surprising, including the small heteronuclear RNA binding protein, Hnrnpk. 


\section{Results}

Establishment of a genome wide high-throughput screen for identification of prion modulators

Scalable, reproducible high-throughput assays should consist of only a few steps and should not require analyte transfers to different reaction containers. Immunochemical prion detection (by Western blotting, enzyme-linked immunoassay, or other methods) is typically preceded by limited proteolysis using proteinase $\mathrm{K}(\mathrm{PK})$, eliminates $\operatorname{PrP}^{\mathrm{C}}$ and ensures that any residual signal is specific to $\operatorname{PrPsc}^{\mathrm{Sc}}$ (Bolton et al., 1982). However, digestion with PK requires fastidious titration and accurate timing, which may introduce confounders (McKinley et al., 1983).

To solve these issues, we took advantage of phosphatidylinositol-specific phospholipase C (PIPLC), an enzyme that cleaves proteins attached to the membrane via a glycophosphatidylinositol (GPI) anchor from the surface of cells (Heinz et al., 1995). While PrPC is GPI-anchored (Stahl et al., 1990), prion aggregates appear to associate in cells independently of the anchoring. PIPLC treatment of intact cells leads to the release of most of the $\mathrm{PrP}^{\mathrm{C}}$ into the supernatant, while prions remain cell associated, (Borchelt et al., 1993; Stahl et al., 1990) and in endocytic compartments (Taraboulos et al., 1992).

Prion assemblies were disaggregated using sodium hydroxide $(\mathrm{NaOH}, \mathrm{pH}=14,66.6 \mathrm{mM})$ (Peretz et al., 2001), neutralized with $\mathrm{NaH}_{2} \mathrm{PO}_{4}$ buffer ( $\mathrm{pH}=4.5,83.3 \mathrm{mM}$ ) to near-neutral $\mathrm{pH}(\mathrm{Li}, 2016)$, and a Förster energy transfer donor-acceptor antibody pair (Allophycocyanin-POM1 (APC-POM1), Europium-POM19 (EU-POM19)) was added (Ballmer et al., 2017; Pease et al., 2019; Polymenidou et al., 2008). PrP was then detected by time resolved (TR) FRET (Ballmer et al., 2017; Heinzer et al., 2021; Pease et al., 2019). We termed the resulting assay QUantltative Prion PhospholipasE pRotection assay (QUIPPER, Fig. 1A).

We then tested our assumption that PIPLC-resistant PrP (henceforth termed "PrPPLC") is a plausible surrogate for prion infectivity. Therefore, we generated chronically RML6-prion infected CAD5 cells (RML CAD5) (Supplementary Fig. 1A) by treatment with mouse brain homogenate containing the Rocky Mountain Laboratory (RML) strain of prions (Avar et al., 2020; Solassol et al., 2003). For control, we used cells inoculated with non-infectious brain homogenate (NBH CAD5). We then measured PrP by QUIPPER and by PK digestion in 384-well microtiter plates. The readout yielded a clear separation between infected and non-infected cells (Fig. 1B). We conclude that QUIPPER can reliably detect prion infection.

Previous reports suggested that PIPLC treatment of chronically infected cells reduces the amount of $\mathrm{PrP}^{\mathrm{Sc}}$ (Enari et al., 2001). In order to ensure that PrPPLC can be used as a surrogate for prion infectivity, 
we performed a scrapie cell assay in endpoint format (SCEPA) (Mahal et al., 2008), arguably the most precise method to determine infectious prion titers in cellula. We inoculated naïve CAD5 cells with three decadic dilutions from lysates of RML-infected CAD5 cells treated with PIPLC just prior to lysis. For control, we used untreated RML CAD5 lysate and PK-treated lysate, as well as naïve and CAD5 ${ }^{\triangle P m p}$ cells inoculated with NBH or RML. After three passages, cells were spotted onto EliSPOT membranes and digested with PK to selectively detect infected cells (Fig. 1C). Image analysis of the optical density of the membranes showed that PrPPLC retained full infectivity associated with prions.

We then compared the discriminatory power of QUIPPER vs. PK digestion for identifying modulators of prion propagation. Chronically infected RML CAD5 and RML GT-1/7 (Supplementary Fig. 1B) cells were treated with Prnp-targeting siRNAs or non-targeting (NT) siRNA controls in 384-well plates. Computation of the Z'-factor, a measure of the separation between positive and negative controls (Zhang et al., 1999), showed that QUIPPER outperformed PK digestion in both RML GT-1/7 and RML CAD5 cell lines (Fig. 1D). We opted to use RML GT-1/7 cells for the genome-wide screen because of their strong adherence to tissue culture plates, which facilitated their handling in 384-well microplates.

\section{Genome-wide screen for prion modifiers}

We used a genome-wide murine siRNA library containing a pool of three distinct siRNAs per target transcript. Each siRNA mixture was dispensed in duplicate to a final concentration of $20 \mathrm{nM}$ using an acoustic dispenser. Each 384-well plate was loaded with 264 gene-targeting siRNA triplets, 22 NT siRNA, and 22 Prnp-targeting siRNAs. The outermost wells were left blank as it was found to be prone to evaporation (Supplementary Fig. 1C). Controls and duplicates were strategically positioned for identifying and correcting any artifactual plate gradients, dispensing errors, or hotspots (Heinzer et al., 2021; Pease et al., 2019). Such gradients can arise from problems with the dispensing and aspiration steps or from temperature/humidity inhomogeneities during the incubation. After three days of culture, RealTime-Glo (RT-Glo), a reagent for cell-viability readout, and PIPLC were added and incubated at 37 ${ }^{\circ} \mathrm{C}$ for two hours. Subsequently, RT-Glo luminescence was measured, medium was aspirated, cells were lysed, and PrPPLC was disaggregated and denatured. Finally, the antibody pairs were added to each well, and TR-FRET was measured after a $24 \mathrm{~h}$ incubation (Fig. 1A).

We screened a total of 136 plates entailing $17^{\prime} 582$ in duplicates using siRNA triplets as well as 2'992 negative and positive controls, respectively. For each plate, heatmaps of TR-FRET and RT-Glo values (Supplementary Fig. 1D) were generated to detect any artifactual signal gradients or hotspots, which 


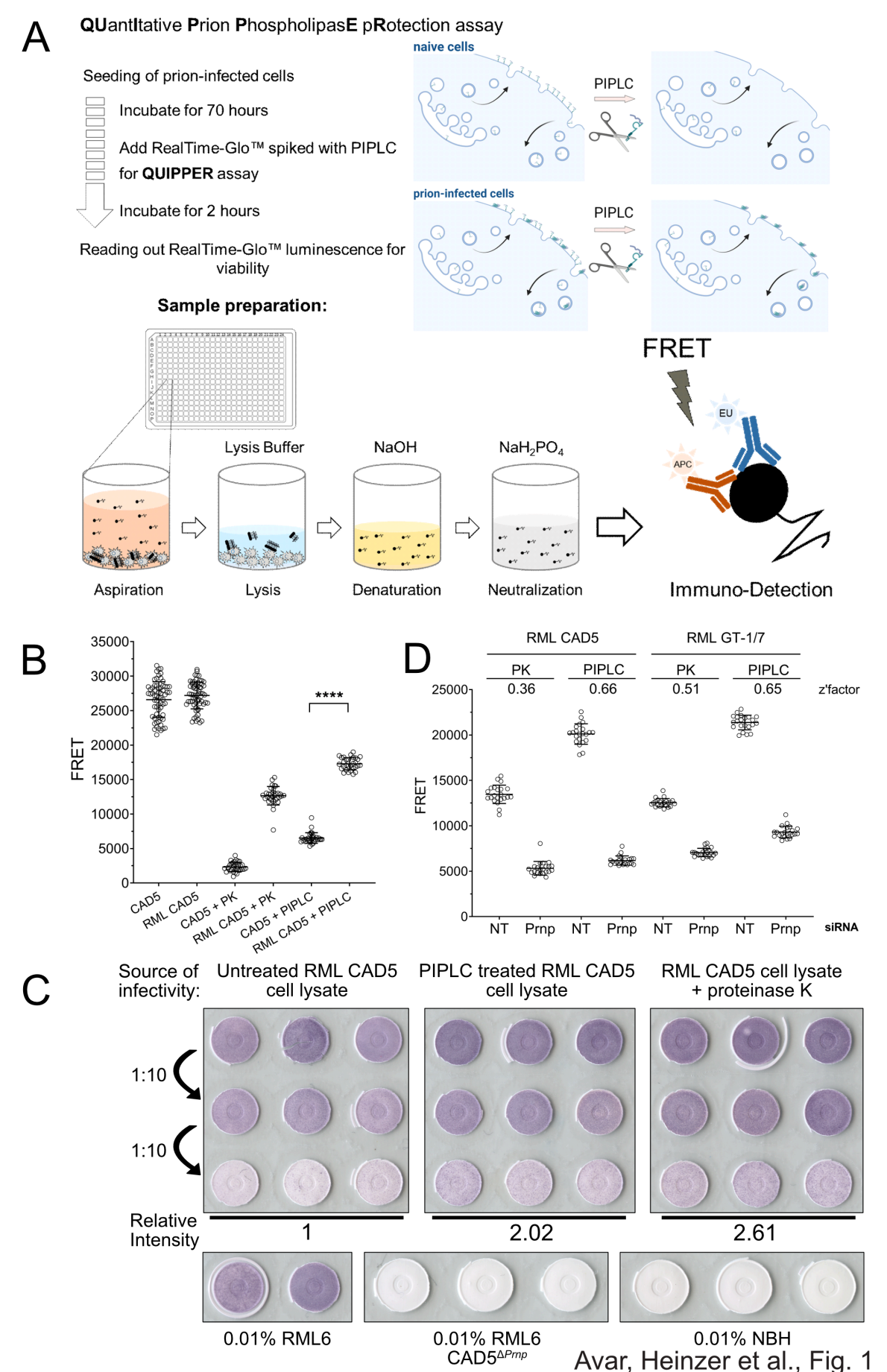

Figure 1. A cell-based high-throughput prion detection assay for an arrayed whole genome RNAi screen. A: Workflow of the QUIPPER assay. B: PK vs. PIPLC treatment to determine prion loads in infected cells in 384-well plates. Both treatments discriminate between RML prion infected CAD5 and non-infectious brain homogenate (NBH) treated CAD5 cells. ${ }^{* * *}=p$-value $<0.0001$, Student's t-test C: The infectivity of PIPLC and PK-treated cell lysates was determined by infecting CAD5 cells with lysates as indicated. The signal intensity of the highest dilution was measured and compared to untreated RML CAD5 cell lysate. PIPLC-treated cells and PK-treated lysates showed similar infectivity titers. Prion-infected and $\mathrm{NBH}$, as well as RML on CAD5 ${ }^{\triangle P r n p}$ were used for control. D: RML-infected CAD5 and GT$1 / 7$ cells were transfected with non-targeting (NT) or Prnp targeting siRNAs in a 384-well plate and subjected to PK or PIPLC treatment. Z'-factors were calculated for each condition.

may have occurred during the screening process. 15'548 genes were assayed in duplicates and 2'030 genes in single measurements; four genes were not assayed during the primary screening. Z'-factors (Zhang et al., 1999) were $>0.5$ for 125 plates and $0-0.5$ for 11 plates, confirming the robustness of the 
bioRxiv preprint doi: https://doi.org/10.1101/2022.03.03.482765; this version posted March 4, 2022. The copyright holder for this preprint (which was not certified by peer review) is the author/funder, who has granted bioRxiv a license to display the preprint in perpetuity. It is made available under aCC-BY-ND 4.0 International license.

screen (Fig. 2A). A plot of all TR-FRET values obtained from the screen showed two non-overlapping populations corresponding to Prnp-targeting and NT controls, whereas the majority of the genes interrogated by the library had no effect on prion levels (Fig. 2B). The determination coefficient $\mathrm{r}^{2}$ between duplicates was 0.38 , indicating a correlation sufficient to enable candidate selection (Taylor, 1990) (Fig. 2C).

We then computed the standard score (z-score) for each candidate (Birmingham et al., 2009), and selected the top scoring 2’515 candidates (z-score=[<-3.5]U[>3.5]) for a confirmatory screen (Fig. 2D). Of these candidates, 2'154 had a negative z-score, whereas only 361 genes had a positive z-score. Hence, $86 \%$ of modifiers, when suppressed, reduced PrPPLC levels, whereas modifiers whose

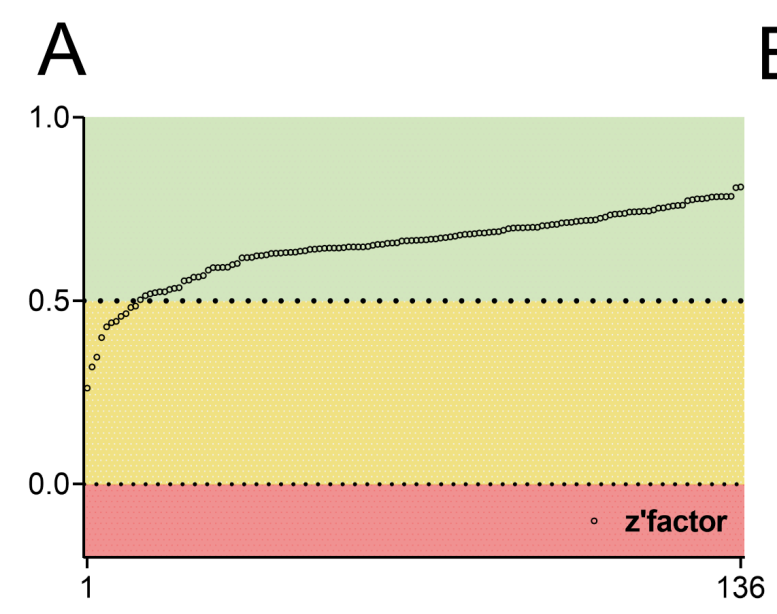

$\mathrm{B}_{2000}$

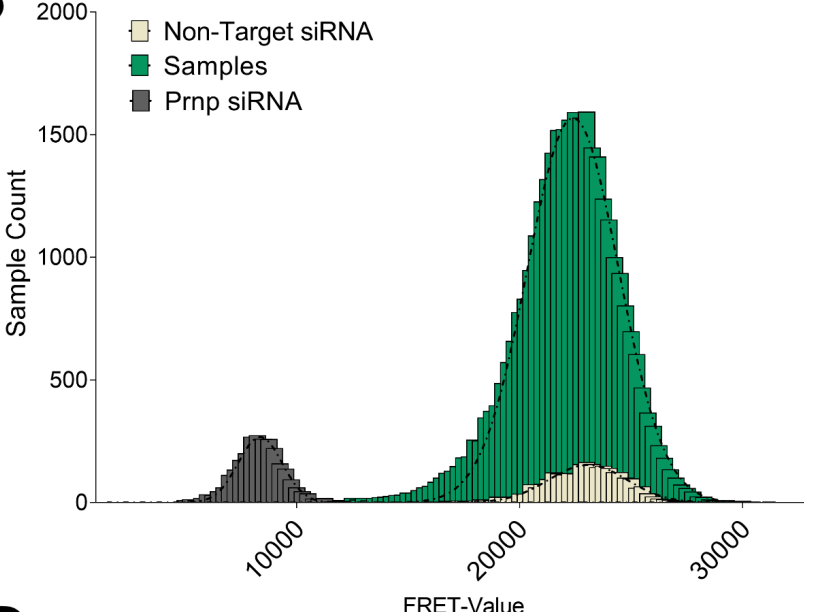

C

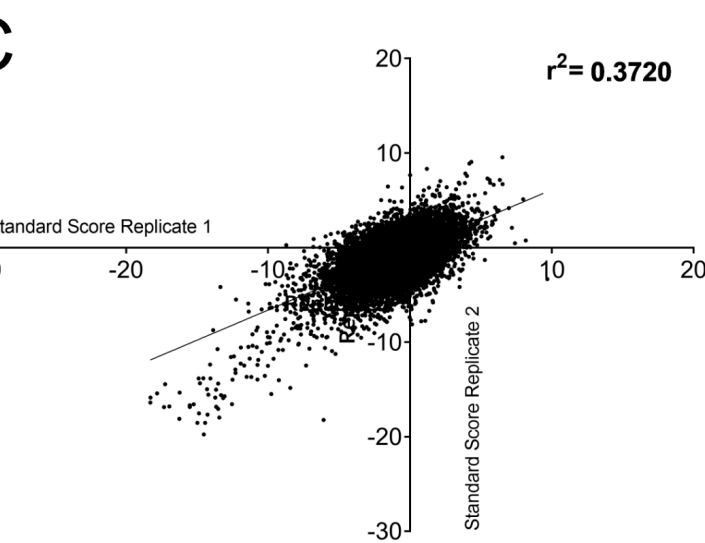

$\mathrm{D}$

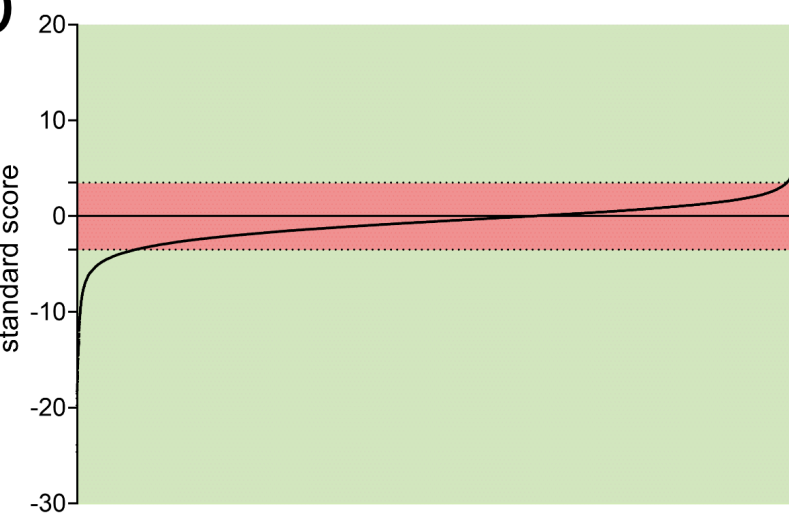

Avar, Heinzer et al., Fig. 2

Figure 2. Whole-genome screen for prion modulators. A: Z'-factor for each plate of the whole genome screen representing the robustness of the screen based on the separability of the positive (Prnp targeting) and negative (nontargeting) controls. B: Histogram representing the influence of each protein-coding gene as well as NT and Prnp targeting controls, on prion levels. Abscissa: prion levels measured by FRET. Ordinate: number of genes yielding a given FRET-range. Controls showed a strong separation, allowing for confident hit-selection. Only few genes affected prion levels. C: Correlation of standard scores for all genes that were assayed in duplicates in the primary screen. $r^{2}$ : coefficient of determination. D: All individual data points from the primary screening. Genes reaching a z-score of [<$3.5] \cup[>3.5]$ in one or both duplicates were considered as hits (green area). 
suppression enhanced PrPPLC levels were rarer (14\%) (for candidate selection process, also see Supplementary Fig. 1E).

\section{Confirmatory screens on prion modulators}

Since $\mathrm{PrP}^{\mathrm{C}}$ is necessary for prion propagation, some prion modifiers may act by changing $\operatorname{PrP}{ }^{\mathrm{C}}$ expression or localization, whereas others may act selectively on PrPsc. We therefore performed two secondary screens. In the first screen, all top-scoring 2'515 hits were tested for the modulation of $\operatorname{PrP} \mathrm{P}^{\mathrm{C}}$. To exclude any potential confounders, GT-1/7 were exposed to NBH and passaged identically to the prion-infected cells, and the assays were performed as in the previous screen except for the omission of PIPLC treatment. In a second screen, we performed QUIPPER on the same 2'515 hits and measured PrPPLC.

All plates passed quality control (Supplementary Fig. 2A) and the reproducibility of duplicates was high ( $\mathrm{r}^{2}$ for the PrPC and PrPPLC subsets: 0.77 and 0.76 for QUIPPER and 0.8 and 0.88 for viability, respectively; Supplementary Fig. 2B and 2C). The TR-FRET scores of duplicates were averaged and a z-score for measuring the effect size of the manipulation of each gene was computed (Supplementary Table 1). The $\operatorname{PrP}^{C}$ and PrPPLC subsets were strongly correlated $\left(r^{2}: 0.62\right)$, suggesting that selective PrP ${ }^{P L C}$ regulators are rare (Fig. $\left.3 \mathrm{~A}\right)$. Moreover, there was a strong correlation between the RT-Glo measurements for NBH and RML infected GT-1/7 cells (Supplementary Fig. 2D), implying that no gene knockdown resulted in synthetic lethality with prion infection under these conditions.

We then applied layered criteria to identify genes modulating specifically $\operatorname{PrP}{ }^{P L C}$. Firstly, in the repetition of the QUIPPER assay, only genes with a z-score $[<-2.58] \cup[>2.58]$, corresponding to a $p$ value of 0.01, were considered hits. Secondly, in order to exclude any genes with a strong impact on viability, we limited the hit calling to samples in which the raw RT-Glo signal was not below $50 \%$ of the platespecific NT control. Thirdly, we considered only genes whose effect size was $\geq 2.58$ standard deviations higher for $\mathrm{PrP}^{\mathrm{PLC}}$ than for $\mathrm{PrP}^{\mathrm{C}}$ in uninfected cells. The latter criterion led to the exclusion of $99 \%$ of the overlap in two datasets. Lastly, all genes fulfilling these criteria were filtered according to their expression levels in RML GT-1/7 cells (Supplementary Table 1), thereby excluding genes that were not expressed (also see Supplementary Fig. 1E). This led to a list of 161 genes whose expression has a stabilizing ( $n=131)$ or limiting $(n=30)$ effect on the amount of PrPPLC (Fig. 3A, blue circles). 
bioRxiv preprint doi: https://doi.org/10.1101/2022.03.03.482765; this version posted March 4, 2022. The copyright holder for this preprint (which was not certified by peer review) is the author/funder, who has granted bioRxiv a license to display the preprint in perpetuity. It is made available under aCC-BY-ND 4.0 International license.

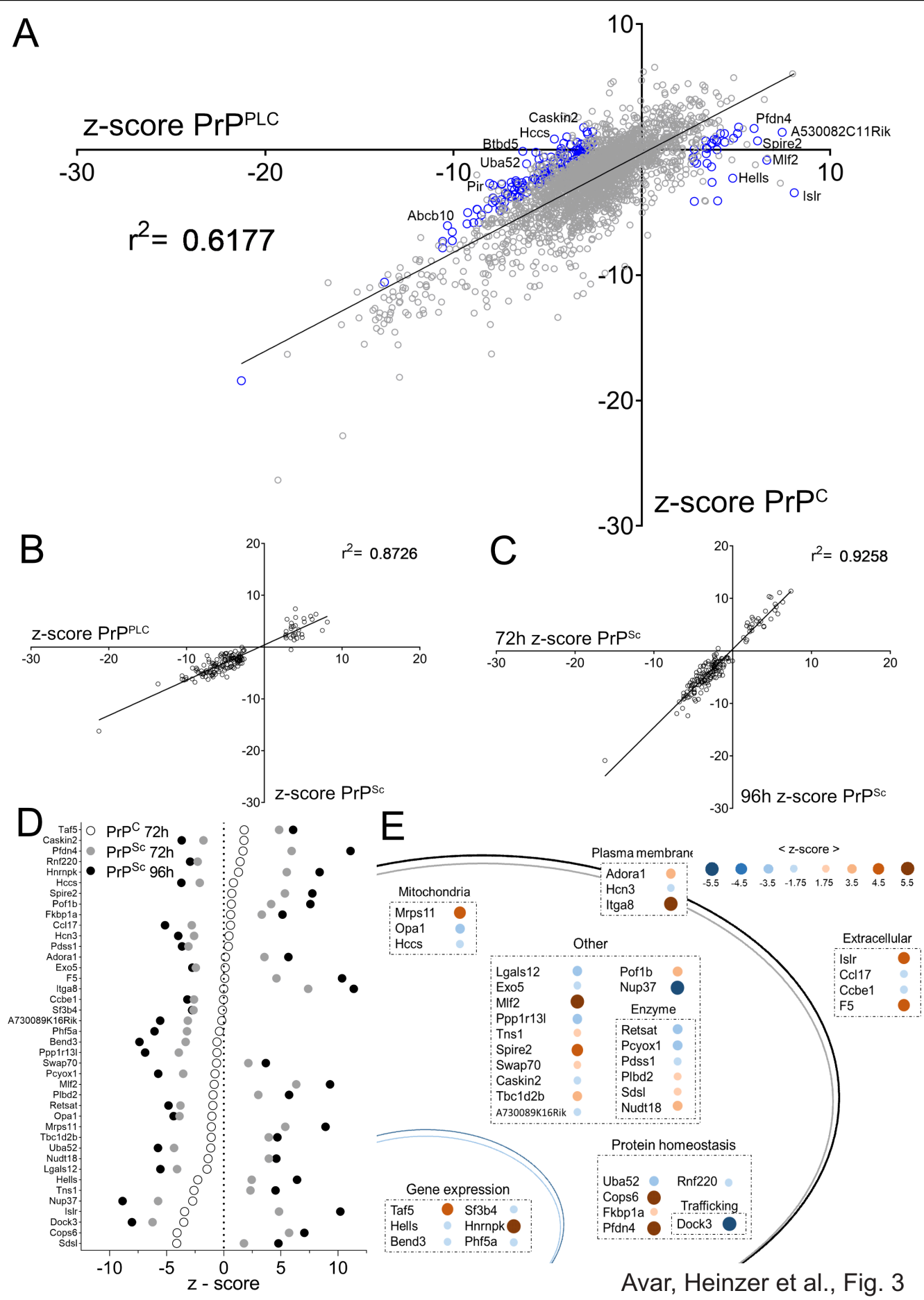

Figure 3. Secondary screens and shortlisting of $\mathbf{4 0}$ candidates

A: Regression of the values of the confirmatory screen for prion specific modulators in mock- and prion infected GT$1 / 7$ cells. Z-scores of genes from the two independent screens, assessing either regulation of $\operatorname{PrP}^{\mathrm{C}}$ or $\mathrm{PrP}^{\mathrm{PLC}}$, yield a coefficient of determination ( $r^{2}$-value) of 0.62 indicating that most genes are modulating prion levels via regulating $\mathrm{PrP}^{\mathrm{C}}$. Blue circles indicate 161 prion specific hits selected for downstream counter screens. The most conspicuous modulators were labelled. B: Correlation of z-scores obtained from a secondary screen to assess the effect of PK digestion on 161 PrPPLC modulators in RML GT-1/7 cells after 72 hours of RNAi treatment. Z-scores of genes from the two independent screens (PIPLC or PK for two different sample preparation approaches) yield a coefficient of determination $\left(r^{2}\right)$ of 0.87 , indicating that the candidates regulate PK-resistant prions. C: Correlation of the z-scores obtained from the counter-screenings to assess the effect of PK digestion on the prion modulators in RML GT-1/7 cells after 72 hours and 96 hours of RNAi treatment. The coefficient of determination ( $r^{2}$-value) of 0.93 and the increase in effect size for the prolonged treatment condition indicate a robust effect of the candidates on prion levels. D: Summary of the effect of the 40 shortlisted hits on $\operatorname{PrPC}^{C}$ (after 72h) and PrPSc (after 72 and 96h), assayed using PK digestion, given as z-scores. E: Function and topology of the 40 hits. Blue dots: prion stabilizers; brown dots: prion limiters. Size and color saturation represent the effect size of each hit based on its z-score (72 hours RNAi treatment; PK readout). 
Role for prion specific modulators in sporadic Creutzfeldt-Jakob disease (sCJD) susceptibility

We wondered whether any of the 161 modulators of PrPPLC may have a role in genetic susceptibility to sCJD (Heinzer et al., 2021). No gene passed the threshold for multiple hypothesis testing. The top ranked association was DOCK3 (Multi-marker Analysis of GenoMic Annotation (MAGMA) unadjusted $p=0.00063$ ), a brain-resident guanine exchange factor serving as a binding partner to presenilin, which is implicated in Alzheimer's disease and neurodegeneration (Bai et al., 2013; Chen et al., 2002; Chen et al., 2009; Tachi et al., 2012) (Supplementary Table 1).

\section{Validation of prion-specific regulators}

Our observations suggest that QUIPPER may detect perturbations of prion propagation more sensitively than PK digestion. However, because QUIPPER is a new assay that has not yet been validated extensively by multiple laboratories, we subjected prion-infected GT-1/7 cells to PK digestion upon treatment with siRNA triplets corresponding to each of the 161 hits after 72 and 96 hours of siRNA treatment. We found a remarkable convergence between the QUIPPER and PK assays over the entire collection of genes (Fig. 3B), represented by the high $r^{2}$ of 0.87 , bolstering our confidence in the robustness of the targets identified. Prolonging the treatment with siRNA enhanced the effects observed (Fig. 3C). We then asked whether the hits were specific to a particular prion strain. For that, we infected GT-1/7 cells with the $22 \mathrm{~L}$ strain of prions (Supplementary Fig. $3 \mathrm{~A}$ ) and treated them with siRNA triplets corresponding to 97 randomly selected hits, filling a 384-well plate. Most genes showed similar effects on RML and 22L-infected cells at both timepoints tested (Supplementary Fig. 3B).

In summary, 40 out of the 161 candidates showed a robust and consistent prion modulation across all detection methods (see Supplementary Figure 1E). 20 out of these 40 candidates reduce prion propagation upon silencing, and 20 candidates enhanced prion propagation, and henceforward are called stabilizers or limiters, respectively (Fig. 3D-E, Supplementary Table 1).

Hnrnpk expression limits of prion propagation in mouse and human cells Intriguingly, the suppression of Hnrnpk, an essential gene whose ablation causes cell death (Tsherniak et al., 2017), strongly enhanced prion levels while changing $\operatorname{PrP}^{\mathrm{C}}$ levels only slightly. Hence, Hnrnpk acts as a limiter of prion propagation (Fig. 3D and Fig. 4A, left panel). We repeated these experiments in hovS, a human cell line expressing ovine but not human $\operatorname{PrP}^{\mathrm{C}}$, which is readily infectible with the PG127 strain of ovine prions (Avar et al., 2020). Again, the downregulation of HNRNPK in prion-infected 
bioRxiv preprint doi: https://doi.org/10.1101/2022.03.03.482765; this version posted March 4, 2022. The copyright holder for this preprint (which was not certified by peer review) is the author/funder, who has granted bioRxiv a license to display the preprint in perpetuity. It is made available under aCC-BY-ND 4.0 International license.

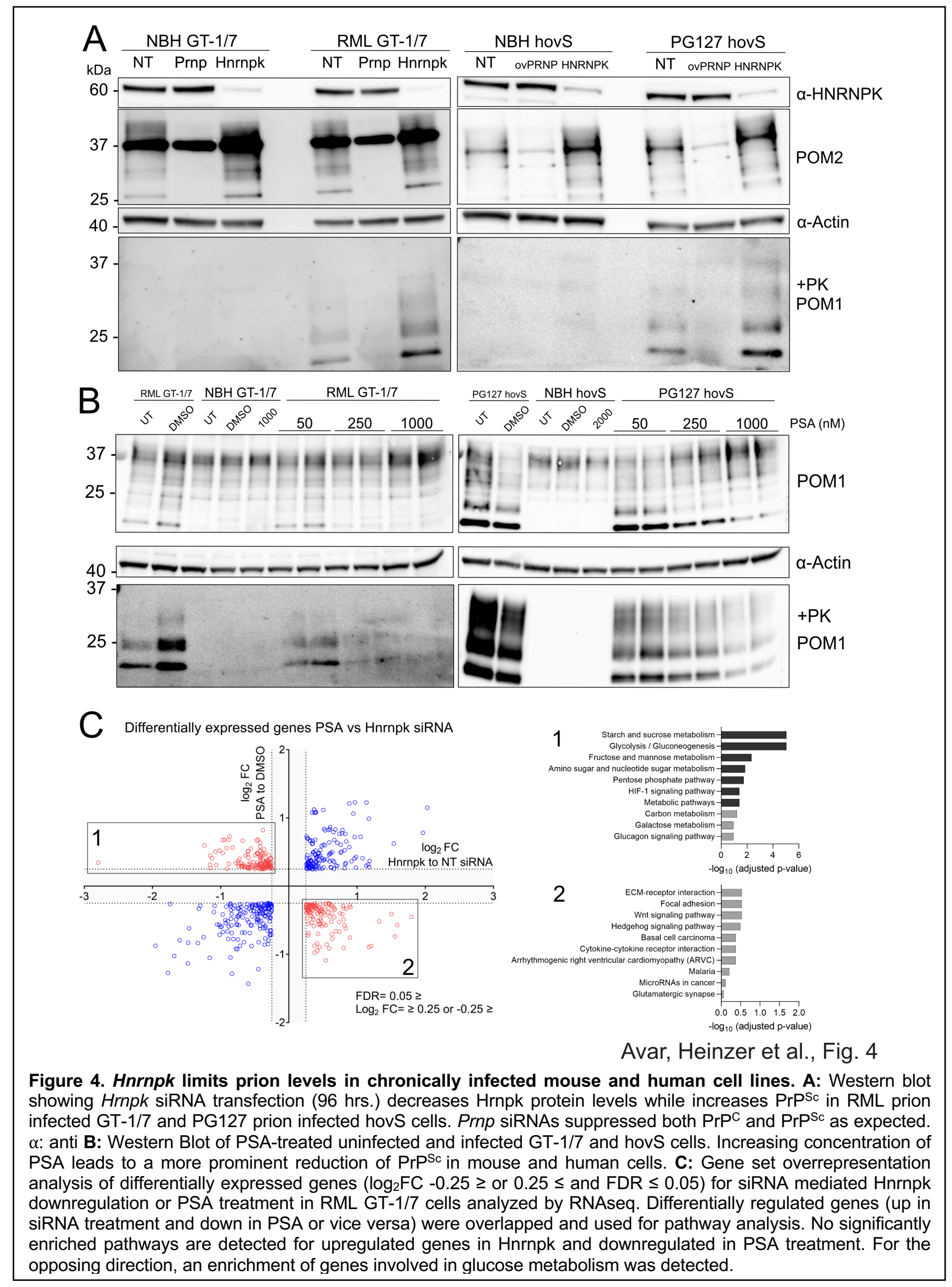

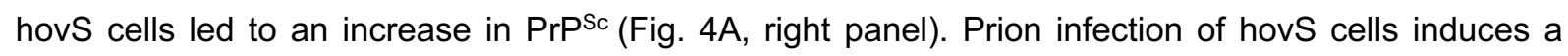
prominent cytopathology consisting of cytosolic vacuolation. HNRNPK suppression exacerbated vacuolation, whereas ovine PRNP (ovPRNP) suppression completely abolished it, in line with the notion 
that prion levels determine the extent of hovS cytopathology (Supplementary Fig. 4A). To validate HNRNPK as a limiter of prion propagation independent of siRNA transfection, the experiment was additionally performed using shRNAs through lentiviral transduction in hovS. The results obtained with a shRNA targeting HNRNPK was congruent to the results obtained via siRNA transfection (Supplementary Fig. 4A and B), again highlighting the validity of HNRNPK as a modulator of prion formation.

To broaden our validation efforts, we treated cells with Psammaplysene A (PSA), which had been described to bind Hnrnpk (Boccitto et al., 2017). PSA treatment led to a dose-dependent decrease of PrPSc in prion-infected mouse and human cell lines (Fig. 4B) whereas $\mathrm{PrPC}^{\mathrm{C}}$ levels remain unaltered (Supplementary Fig. 4C). Next, we asked whether PSA indeed works on regulating PrPSc levels through its interaction with HNRNPK. As a knockout was not possible, due to the cell-essential nature of HNRNPK (Tsherniak et al., 2017) for long-term suppression, we used the shRNA constructs (HNRNPKtargeting and NT) and applied PSA at a concentration of $1 \mu \mathrm{M}$ and started treatment 2 days after lentiviral transduction of shRNAs to allow time for HNRNPK downregulation to take place, and continued PSA treatment for 5 days. PK-digested western blots (Supplementary Fig. 4D) first confirmed that PSA does indeed reduce prion levels in combination with a NT shRNA construct and second, PSA's effect does seem to be limited when HNRNPK shRNAs are applied. Moreover, we found that PSA does not alter HNRNPK levels (Supplementary Fig. 4D) and thus its antiprion effect potentially arises through enhancing the activity of HNRNPK.

We then performed RNAseq of RML GT-1/7 cells treated either with siRNAs against Hnrnpk or with PSA. As siRNA treatment increases prion levels and treatment with PSA leads to a decrease in prion levels, we intersected differentially expressed genes in opposing directions for both treatments. No significant enrichment was detected for genes that are upregulated in the siRNA treatment and downregulated in the PSA treatment. However, when genes that are downregulated in the siRNA treatment condition and upregulated in the PSA treatment condition were taken into account, genes related to glucose metabolism showed a significant enrichment (Fig. 4C).

Psammaplysene A treatment leads to decrease in prion levels ex vivo and in vivo

We then asked whether a reduction of prions would be possible in a more physiological model system for prion infection and propagation. We found cerebellar organotypic cultured slice (COCS) (Falsig and Aguzzi, 2008) to be an ideal model to assess the efficacy of PSA treatment, as it represents a primary cell culture system with all relevant cell types represented as they are in vivo, while allowing easy 
experimental manipulation in a dish system. Therefore, we infected the cultures with prions using RML and started treatment of $1 \mu \mathrm{M}$ PSA diluted in culture medium two weeks post-infection. Subsequently the COCS were homogenized and PK-resistant PrPsc amount was assessed with immunoblotting. We found that PSA treatment following prion infection significantly reduced prion levels (Fig. 5A), without altering $\operatorname{PrP}^{\mathrm{C}}$ levels (Fig. 5B) further highlighting Hnrnpk as a limiter of prion propagation. Furthermore, we took advantage of a Drosophila model of prion propagation for the testing of in vivo efficacy of PSA. The model takes advantage of the ectopic overexpression of ovine $\mathrm{PrP}^{\mathrm{C}}$ in Drosophila melanogaster (Thackray et al., 2018). Following prion infection, which is achieved through feeding the larvae with prion-containing food, flies produce bona fide prions and suffer from neurotoxicity associated with prions, which can be assessed with a negative geotaxis climbing assay. The experiment was performed as previously described (Thackray et al., 2018) and constant PSA treatment was achieved through feeding flies with the compound over the time course of 40 days. During this period, flies were subjected to a negative geotaxis climbing assay to assess whether locomotor deficits upon prion infection showed any improvement by treatment with PSA. Strikingly, a dose-dependent improvement of the performance of the animals was observed (Fig. 5C). Moreover, to address if the amelioration of the locomotor function corresponds to a reduction of prions, an RT-QuIC assay was performed to assess the amount of seeding active prions in the fly brains. Therefore, whole-head homogenates from 20 animals per treatment group were prepared and the samples were diluted 1:20 in PBS prior to their introduction into the RT-QuIC. Whereas flies treated with NBH and subsequently fed DMSO as controls yielded the same outcome as the prion-negative sample, an early peak in ThT signal were observed for flies that have been prioninfected and were later control fed using DMSO (Fig. 5D). Remarkably, a dose-dependent reduction of seeding active prions was observed in response to PSA treatment of flies infected with prions, as quantified based on the lag time (Shi et al., 2013) corresponding to the negative geotaxis climbing assay, demonstrating that PSA can alter prion levels in vivo in Drosophila. 
A
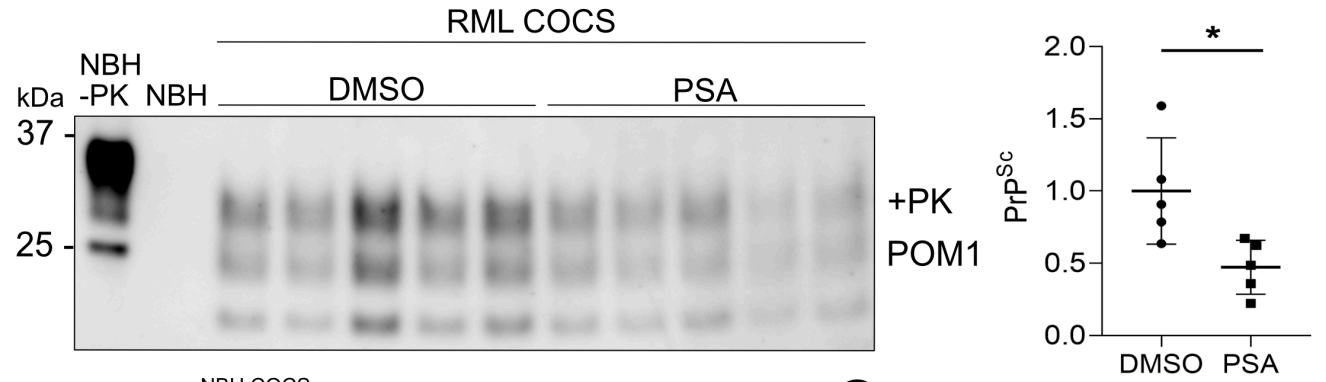

B

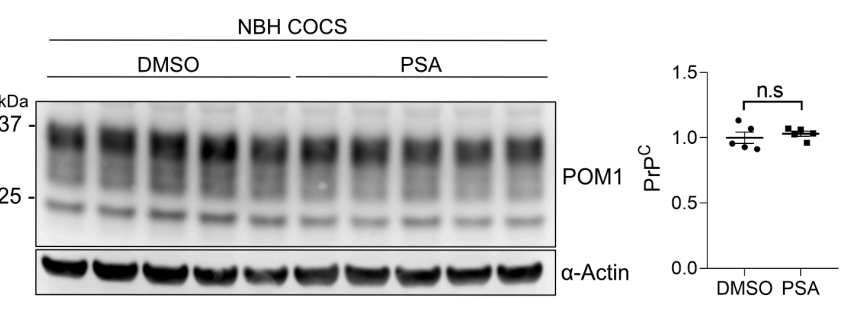

C
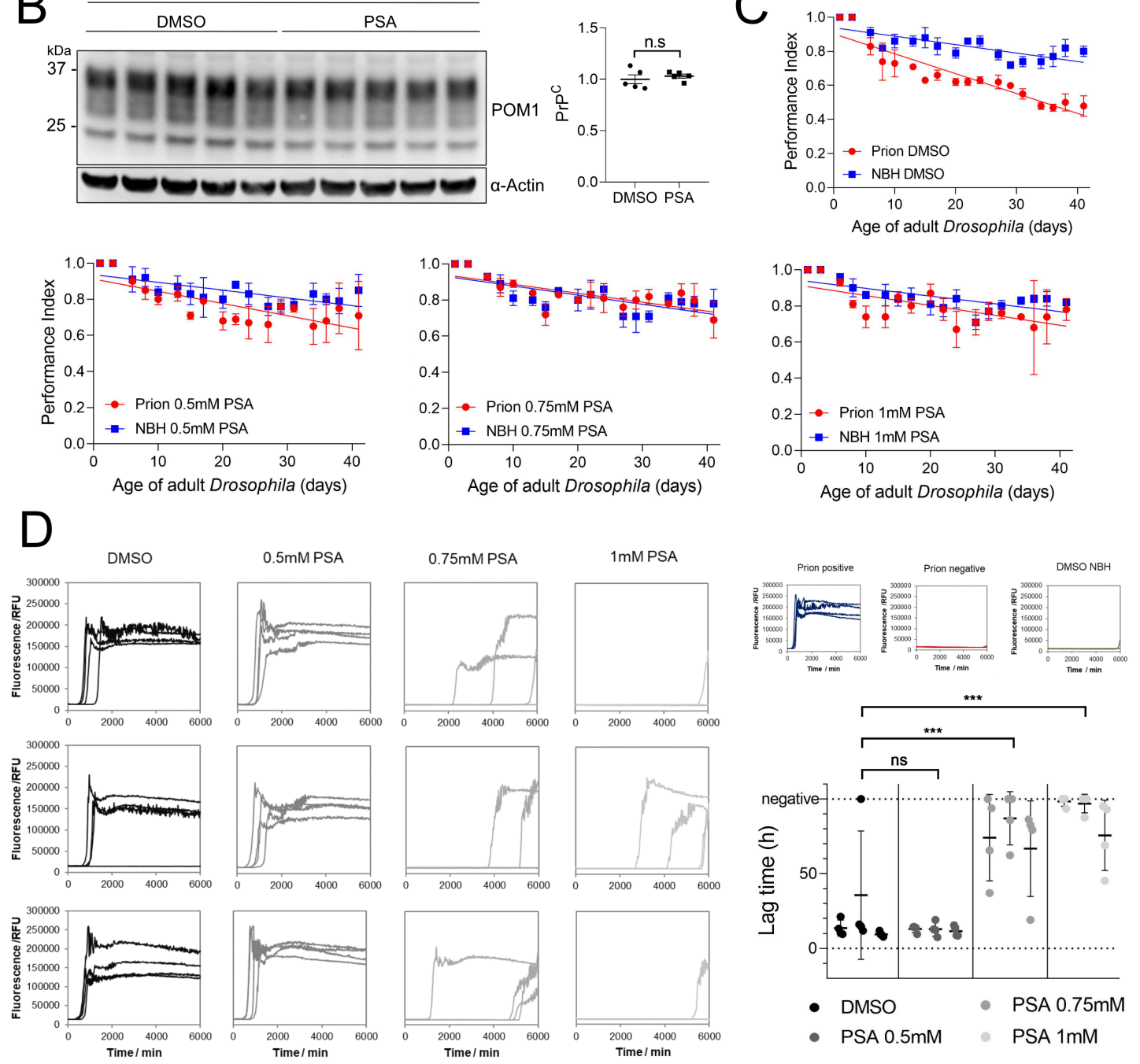

Avar, Heinzer et al., Fig. 5

Figure 5. PSA reduces prion formation ex vivo and in vivo A: Western Blot of RML prion infected COCS treated with $1 \mu \mathrm{M}$ PSA or DMSO. PSA treatment was started two weeks after infection and continued until lysis. PSA reduced the amount of PrPSc. Right panel: Quantification of the Western Blot; Values: mean \pm SD. * $p=00211$ (Student's t-test). $\alpha$ : anti B: Western Blot analysis of NBH-treated COCS. PSA treatment was identical to the samples of A. PSA did not affect PrPC expression. Right panel: Quantification of the Western Blot: Values represent mean \pm SD. n.s. $=$ not significant (student's t-test). C: Negative geotaxis climbing assay in prion infected Drosophila. Flies were treated with DMSO, $0.5 \mathrm{mM}$ PSA, $0.75 \mathrm{mM}$ PSA, or $1 \mathrm{mM}$ PSA at the larval stage and during adulthood for the duration of the assay. Climbing ability was assessed on groups of flies $(n=3 \times 15)$ three times a week and expressed as a performance index. Statistical analysis on the difference between PG127 prion infected versus control prion-free treatment group data in each graph was performed by an unpaired t test: DMSO: $p=0.0002 ;$ PSA: 0.5 mM: $p=0.0186 ; 0.75 \mathrm{mM}: p=$ n.s.; $1 \mathrm{mM}: p=$ n.s. n.s. = not significant. D: RT-QulC analysis of whole-head homogenates of prion infected Drosophila. For each sample, 10 male and 10 female heads from the same treatment group were homogenized, 1:20 diluted and applied to the RT-QuIC. Shown are the RT-QuIC reactions of three independent homogenates per treatment group, each assessed in quadruplicates. For quantification, the lag-time of each reaction was calculated and plotted in a graph. The assays were performed for 100 hours, samples not yielding a positive reaction are considered negative. ${ }^{* * *}=p \leq 0.0006$, n.s. = not significant, flies fed with NBH and treated with DMSO were used as a negative control, a standard prion-free and a prion-containing sample were used as assay controls. 


\section{Discussion}

Most previous attempts to identify prion modifiers were designed to test individual, biologically plausible candidate genes, which have been successful for example by uncovering the essential role of the B-cell receptor (Klein et al., 1997) and the CXCR5 chemokine receptor (Prinz et al., 2003) in prion propagation. Here, we attempted a radically different approach by performing a functional genomic screen to identify prion modifiers in cultured cells, with the only ideological constraint that all tested genes are proteincoding. Classically, prion detection relies on limited proteolysis, e.g. using proteinase K (Bendheim et al., 1984). As this approach is complex and imprecise, and therefore unsuitable to high-throughput screens, we have developed the QUIPPER, a robust method for the quantitative, sensitive, and scalable detection of prion propagation in cultured cells. The principle of QUIPPER relies on the finding that at steady state most $\mathrm{PrP}^{\mathrm{C}}$ resides at the cell membrane and can be released by digesting with PIPLC, whereas prions remain associated to the cells (Borchelt et al., 1993; Stahl et al., 1990). We termed the identified PrP species $\operatorname{PrP}{ }^{P L C}$ as it represents a mixture of prions and $\operatorname{PrP}^{C}$ from the endocytic compartments. To then allow the detection of PrPPLC, sodium hydroxide was added to induce disaggregation, enabling the recognition of the monomers by FRET donor-acceptor antibodies upon $\mathrm{pH}$ neutralization (Pease et al., 2019). Notably, the entire QUIPPER procedure is carried out as a one-pot assay, which greatly enhances its throughput and allows for extensive automation with programmable liquid handlers. Accordingly, QUIPPER enabled us to perform a whole-genome functional genomics screen using RNAi in chronically prion-infected mouse cells. Although we chose to employ QUIPPER in the context of a genetic screen, we believe that it will also be indispensable for future high-throughput drug discovery campaigns in search of antiprion compounds.

Following testing of the whole genome, a secondary screen consisting of 2515 candidates was performed and additionally assessed for changes in the levels of $\mathrm{PrP}^{\mathrm{C}}$. Unsurprisingly, most of the primary candidates were regulating $\mathrm{PrP}^{\mathrm{PLC}}$ by affecting the biosynthesis or degradation of $\mathrm{PrP}^{\mathrm{C}}$ and PrPPLC specific regulators were rare. In addition, regulators of $\mathrm{PrP}^{\mathrm{C}}$ demonstrated the strongest effects on prion levels, arguing for modulation of $\mathrm{PrP}^{\mathrm{C}}$ as a potent and valid target in prion diseases (Raymond et al., 2019; Vallabh et al., 2020). Nevertheless, we selected 161 candidates showing an enhanced effect on PrPPLC and assessed those with classical PK digestion to identify modulators of $\mathrm{PrP}^{\mathrm{Sc}}$, as some of the candidates might affect $\mathrm{PrP}{ }^{\mathrm{PLC}}$ levels by changing the localization of $\mathrm{PrP}^{\mathrm{C}}$, rendering it insensitive to PIPLC digestion. Thereby, we identified 40 hits that modulated prion levels, withstanding different biochemical prion detection methods. Among those, we reassuringly found hits that have been 
previously associated with prion disease (Marbiah et al., 2014; Wu et al., 2019), confirming the validity of our approach. When interrogated, these 40 hits did not reveal any significant associations with each other, such as working in concert on a known pathway or as interaction partners. However, it did not escape out attention that a group of hits have been previously associated with other neurodegenerative diseases (Bampton et al., 2021; Banerjee et al., 2017; Caminati and Procacci, 2020; Chen et al., 2001; Schludi et al., 2017; Stone et al., 2009; Takano et al., 2014), implying that there might be common host factors responsible for the progression of these ailments. One of them is Pfdn4, a member of the prefoldin complex (Takano et al., 2014), responsible for the folding of native peptides into their functional form. Although the occurrence of cytosolic $\mathrm{PrP}^{\mathrm{C}}$ and its involvement in the formation of prions remains controversial (Ma and Lindquist, 2001; Ma and Lindquist, 2002; Ma et al., 2002), Prefoldin might be shielding cytosolic $\mathrm{PrP}^{\mathrm{C}}$ from being accessed by prions, thereby preventing its incorporation, as upon downregulation of Pfdn4 we observed a strong increase in $\mathrm{PrP}^{\mathrm{Sc}}$ levels. In addition, we identified several targets (Pof1b, Spire2, Swap70, Tns1, Dock3 and Itga8) that were independently described to be involved in actin binding or dynamics. Such a high prevalence might demonstrate the importance of the host-actin network in the cellular propagation of misfolded proteins. Indeed, actin has been shown to influence prion propagation in yeast (Dorweiler et al., 2020) and might be applicable as well in mammalian cells (See et al., 2021; Victoria and Zurzolo, 2017). Based on our data, the actin network might be a worthwhile target to further investigate. In addition, previous studies have shown promising results in modulating the propagation of pathological aggregates by interfering with the actin network (Rostami et al., 2017), in which actin may be a major component for cell-to-cell transmission of aggregates, through regulating processes such as synaptic vesicle exocytosis and others (Oliveira da Silva and Liz, 2020).

We put efforts forth in investigating Hnrnpk as a prion modulator, due to its strong effect size, ubiquitous expression (Uhlén et al., 2015), and its recent implications in several protein misfolding diseases (Bampton et al., 2021; Moujalled et al., 2015; Sidhu et al., 2022). As Hnrnpk is a cell-essential gene (Tsherniak et al., 2017), we followed several lines of validation in human and mouse cells as well as different modes of genetic perturbation. In all instances tested, HNRNPK downregulation led to an increase in prion levels, leading to the conclusion that HNRNPK is a host-factor regulating prion formation, irrespective of prion strain and even species in question. Moreover, in our human cell model for prion propagation, we found that the application of siRNAs and shRNAs targeting HNRNPK, led to a robust increase in prion-induced cytopathological vacuolation, and targeting $\operatorname{PrP}^{\mathrm{C}}$ completely abolished 
it. In addition, a neuroprotective compound, Psammaplysene A, reported to bind Hnrnpk (Boccitto et al., 2017), allowed us to investigate the target pharmacologically. Psammaplysene A (PSA) application in vitro, ex vivo and in vivo, relieved prion propagation and ameliorated prion toxicity in a dose-dependent manner and therefore acts as a potent inhibitor of prion formation, repeatedly, independent of species in question and prion strain, in contrast to most other anti-prion drugs, which have been limited in their effect for different prion strains (Ghaemmaghami et al., 2010). The conclusions of this are twofold: First, it demonstrates the possibility and effectiveness of targeting a host-resident factor in prion diseases. Second, it suggests that different prion strains rely on the same host-factors for effective propagation, implying that host factors might provide efficient anti-prion targets independent of prion strains. Although the mode of action of PSA and its effect on Hnrnpk could so far not be clarified, we posit that Hnrnpk's endogenous anti-prion function is enhanced upon PSA treatment, as we found no difference in Hnrnpk levels following PSA treatment. Since PSA only binds to Hnrnpk in the presence of RNA (Boccitto et al., 2017), therefore, potentially interfering with its RNA binding properties, RNA-binding of Hnrnpk might be crucial for limiting prion propagation by limiting the amount of free RNA which has been described as a potential scaffolding factor for the formation of prions (Deleault et al., 2003). Investigation of or mimicry of its function might provide a novel therapeutic approach for prion diseases and potentially other neurodegenerative diseases. Moreover, we are confident that other prion modifiers discovered in this study will be of great use to investigate cellular mechanisms of prion propagation, and perhaps represent general cellular host-factors of protein aggregation. 


\section{Materials and Methods}

\section{Cell culture}

GT-1/7 cells (AccessionID: CVCL_0281, (Mellon et al., 1990), CAD5 cells (CATH-A-Differentiated, AccessionID: CVCL_0199, (Mahal et al., 2008), hovS cells (ovinized SH-SY5Y cells, produced in house) were cultured in T75 or T150 tissue culture flasks (TPP, Trasadingen, Switzerland) in OptiMEM containing Phenol unless stated otherwise (Gibco, Thermo Fisher Scientific, Waltham, MA, USA). As supplements $10 \%$ of FBS (Takata, Göteborg, Sweden), $1 \%$ of Non-Essential Amino Acids (NEAA, Gibco), $1 \%$ GlutaMaX (Gibco) and 1\% of Penicillin/Streptomycin mix (P/S, Gibco) were used. During the screening process phenol was omitted from the media using a no-Phenol formulation for OptiMEM (Gibco), to eliminate a potential interference with the TR-FRET readout. During harvesting of the cells Accutase (Gibco) was used and collection of the detached cells was done using 1X phosphate buffered saline (PBS, Kantonsapotheke Zurich, Switzerland or Gibco) followed by centrifugation at $1400 \mathrm{rpm}$ (Sorvall Legend XT, Thermo Fisher Scientific) for four minutes with the aim of eliminating dead cells. Later, cell counting was done using trypan blue (Gibco). For culturing hovS cells, $400 \mu \mathrm{g} / \mathrm{mL}$ geneticin (G418 sulfate, Life Technologies, Gibco) was added to the media. For freezing of the cell culture stocks, cells were resuspended in Bambanker Freezing Medium (LubioScience, Zurich, Switzerland) or DMSO (Sigma Aldrich, St. Louis, MO, USA) containing $10 \%$ FBS and stored in $-80{ }^{\circ} \mathrm{C}$ or a liquid nitrogen tank, respectively.

\section{Prion infection of cells}

For infection of cells with different strains of prions, a previously established protocol was followed (Avar et al., 2020). Cells were seeded in 6-well plates and the infection occurred for all prion strains (22L, RML, PG127) at the same weight/volume ratio of $0.25 \%$ brain homogenate containing prions or noninfectious brain homogenate (NBH) in a total culture media volume of $1.5 \mathrm{~mL}$. Cells were incubated together with the infectious material for three days, followed by continuous splitting for eight passages to ensure a state of persistent prion infection was achieved.

\section{siRNA library preparation and screening}

The whole genome Silencer Mouse siRNA library Version 3, consisting of three unique siRNAs targeting each annotated 17582 mouse gene (52746 siRNAs) was purchased from Thermo Fisher Scientific in a lyophilized format amounting to $0.25 \mathrm{nmol} / \mathrm{siRNA}$. The library was resuspended, pooled and aliquoted in house as described (Heinzer et al., 2021) to a final concentration of $5 \mu \mathrm{M}(1.67 \mu \mathrm{M}$ each). For the screening procedure, the aliquoted pooled library was reformatted into the destination plates (384-well 
Cultur Plate, Perkin Elmer, Beaconsfield, UK) along with the Prnp targeting (Thermo Fisher Scientific) positive controls, NT controls (Thermo Fisher Scientific) serving as negative control and a cell deathinducting control (Qiagen, Hilden, Germany) to make up a final concentration of $20 \mathrm{nM}$. Plates were frozen at $-40{ }^{\circ} \mathrm{C}$ until further use. On the assay day, plates were thawed and $5 \mu \mathrm{L}$ of RNAiMAX (Invitrogen, Carlsbad, CA, USA) diluted in culture media without antibiotics ( $3 \% \mathrm{v} / \mathrm{v})$ to a final concentration of $0.5 \%$ was dispensed with a Biotek MultiFlo FX multi-drop dispenser (Vinooski, VT, USA), followed by centrifugation (1000 rpm, 1 minute, Eppendorf 5804R, Hamburg, Germany) and subsequently the plates were incubated for 30 minutes at room temperature (RT). Later, cells (RML GT$1 / 7$ or $22 \mathrm{~L}$ GT-1/7, NBH GT-1/7, RML CAD5, NBH CAD5) were seeded on top of the siRNA-RNAiMAX mixture at a density of 12500 cells/well (3000 cells/well for RML CAD5 and NBH CAD5) in a total volume of $25 \mu \mathrm{L}$ to achieve reverse transfection. Cells were incubated in a rotating tower incubator (LiCONiC StoreX STX, Schaanwald, Liechtenstein) for 70 hours and were removed for viability measurements. To measure the viability of cells, $10 \mu \mathrm{L}$ of $4 \mathrm{X}$ concentrated Realtime-Glo (RT-Glo) reagent (Promega, Madison, WI, USA) diluted in antibiotic-free medium was dispensed. In addition, for the screening rounds involving a PIPLC readout, the enzyme was spiked into the media containing the viability reagent at a dilution of $1: 800$ and plates were returned to the rotating incubator for further incubation for another 2 hours. Subsequently, the luminescent signal was read out in an EnVision multimode plate reader (Perkin Elmer) at $37^{\circ} \mathrm{C}$. For the sample preparation with the PIPLC readout, culture media was aspirated from the plates using a Biotek EL406 plate washer and lysed with $13 \mu \mathrm{L}$ of lysis buffer containing $0.5 \% \mathrm{Na}$ deoxycholate (Sigma Aldrich), 0.5\% Triton-X (Sigma Aldrich) and EDTA-free cOmplete Mini protease inhibitor cocktail (Roche, Basel, Switzerland). The lysis of the contents of the wells was performed on a plate shaker (Eppendorf Thermo Mixer Comfort) for 10 minutes at $4{ }^{\circ} \mathrm{C}$ at $500 \mathrm{rpm}$ shaking, followed by an additional incubation step at $4^{\circ} \mathrm{C}$ in still standing position for 1 hour. B. cereus PIPLC was produced in house as described previously (Hornemann et al., 2004; Ryan et al., 1996) in E. coli. For the PK readout, the protease inhibitor was omitted from the lysis buffer contents. Instead, the lysis buffer was spiked with a $2.5 \mu \mathrm{g} / \mathrm{mL}$ final concentration of $\mathrm{PK}$, dispensed $10 \mu \mathrm{L}$, incubated for 30 minutes on a plate shaker at $37{ }^{\circ} \mathrm{C}$ with shaking, followed by addition of $3 \mu \mathrm{L}$ of final $2.3 \mathrm{mM}$ phenylmethylsulfonyl fluoride (PMSF, a serine hydrolase inhibitor) (Sigma Aldrich) diluted in PBS/isopropanol (Sigma Aldrich) mixture and incubated on a plate shaker for 10 minutes at RT and $500 \mathrm{rpm}$ shaking conditions. For both the PIPLC and the PK readouts, the following steps involving denaturation and neutralization for sample 
preparation as well as the TR-FRET procedure for the final readout were identical. Denaturation was performed by dispensing $2 \mu \mathrm{L}$ of $0.5 \mathrm{M} \mathrm{NaOH}$ to a final concentration of $66.6 \mathrm{mM}$ and plates were shaken with $500 \mathrm{rpm}$ at RT for a total of 2 minutes followed by 8 minutes more of incubation time in still standing position. Denaturation of the fibrils was followed by a neutralization step to adjust the $\mathrm{pH}$ of the contents of the wells prior to the addition of the antibodies. $3 \mu \mathrm{L}$ of $0.5 \mathrm{M} \mathrm{NaH}_{2} \mathrm{PO}_{4}$, was added to make up a final concentration of $83.3 \mathrm{mM}$ and plates were shaken once more with $500 \mathrm{rpm}$ at RT for a total of 2 minutes followed by 7 minutes more of incubation time in still standing position. For the read-out of $\operatorname{PrP}^{\mathrm{C}}$ levels in the deconvolution screen, the usage of PIPLC, as well as the subsequent sample preparation steps were omitted. Instead, cells were lysed in $18 \mu \mathrm{L}$ of lysis buffer. Finally, for all the approaches, $9 \mu \mathrm{L}$ of TR-FRET antibody pairs, POM1 (Polymenidou et al., 2008) coupled to Allophycocyanin (APC) and POM19 coupled to Europium (EU) as previously described (Ballmer et al., 2017; Heinzer et al., 2021) were added to a final concentration of 5 and $2.5 \mathrm{nM}$, respectively. After each dispensing step during sample preparation and TR-FRET, plates were centrifuged at $1000 \mathrm{rpm}$ for one minute. Plates were returned to the fridge for incubation overnight and read out on the following day on the EnVision (Perkin Elmer) plate reader with the previously described parameters (Ballmer et al., 2017).

\section{Data Analysis}

Screening data was analyzed in the same way as previously described (Heinzer et al., 2021). Data quality and robustness was assessed at several steps during the analysis pipeline. Heatmaps were visually inspected for any occurrence of gradients, arising through dispensing errors. Wells with prominent dispensing errors were excluded from further analyses during the primary screen. Z'-Factor (Zhang et al., 1999; Zhang, 2011) was computed for each plate as a metric for separability of the positive (Prnp targeting siRNAs) and negative (NT siRNAs) controls. Net-FRET and z-score values for each candidate were calculated and regressed onto each other for assessing the reproducibility of the duplicates. Hit selection was based on the z-scores of each gene, as explained in the results section of this manuscript. Results were depicted using GraphPad Prism.

\section{RNA-Seq experiments}

RNeasy Mini Kit (Qiagen) was used for RNA-extraction according to the manufacturer's guidelines. Libraries were prepped with the Illumina TruSeq stranded mRNA protocol (Illumina, San Diego, CA, USA) and quality control (QC) was assessed on the Agilent 4200 TapeStation System (Agilent Technologies, Santa Clara, CA, USA). Subsequently, libraries were pooled equimolecular and sequenced on the Illumina NovaSeq6000 platform with single-end 100 bp reads. Sequencing depth was 
around 20 million reads per sample. Experiments were run in biological duplicates, unless otherwise stated. Data analysis was done using a previously established pipeline (Hatakeyama et al., 2016) (Supplementary Table 1). Pathway analysis for significantly enriched cellular processes or components were done using WEB-based GEne SeT AnaLysis Toolkit (WebGestalt) (Wang et al., 2017) using the KEGG functional category version 88.2 dated 11/01/2018.

siRNA transfections and PSA treatment in large-well format

Cells were seeded at a density of 500 '000 cells/well for RML GT-1/7 and 450'000 cells/well for PG127 hovS in $1.5 \mathrm{~mL}$ of culture medium in 6-well plates (TPP). Next day, media was exchanged with optiMEM (Gibco) with no antibiotics. To enable efficient transfection, RNAiMAX (Thermo Fisher Scientific) with the same concentration as in the screening process was added (final conc. for hovS: $0.3 \%$ ). Next day, siRNAs diluted in water were mixed with RNAiMAX and a final concentration of $20 \mu \mathrm{M}$ (10 $\mu \mathrm{M}$ for hovS) was administered to the culture media in a dropwise manner to achieve forward transfection. Incubation lasted 72 or 96 hours, as indicated per experiment. Media containing siRNAs was aspirated and cells were washed once with 1X PBS (Kantonsapotheke) and lysed for downstream analysis. Imaging of the cells was performed using a Nikon T2 Eclipse (Nikon, Tokyo, Japan) microscope and images were processed using ImageJ (Schneider et al., 2012). PSA (Aobious Inc., Gloucester, MA, USA) was freshly prepared at the beginning of any experiment by serial dilution in DMSO. For each concentration, one aliquot per day of treatment was stored at $-20^{\circ} \mathrm{C}$. The desired final concentrations of PSA were prepared daily by diluting 1 to 1000 the DMSO stock aliquot in culture media. In the PSA experiments, the cells were seeded in a total volume of $1.5 \mathrm{~mL}$ media in six-well plates at a density of 300'000 PG127 and NBH hovS cells $450^{\prime} 000$ and RML and NBH GT-1/7 cells/well. From the following day for the next 5 days, daily medium changes were performed with freshly prepared media at differing concentrations of PSA.

\section{Immunoblotting}

Lysed cells were centrifuged at 2'000X G for 5 minutes. BCA assay (Pierce, Thermo Fisher Scientific) was used to measure the total protein content of each sample and for all downstream analysis involving proteins, sample volume was adapted to contain the same amount. For immunoblotting, samples were prepared, diluted to achieve the same total protein concentration, and digested using PK (final concentration $2.5 \mu \mathrm{g} / \mathrm{mL}$ ). Digestion was stopped with boiling the samples after addition of $1 \mathrm{mM}$ final Dithiothreitol (DTT, Bio-Rad, Hercules, CA, USA) in NuPAGE 4X LDS loading buffer (Thermo Fisher Scientific). Samples were then loaded onto a NuPAGE 4-12\% Bis-Tris gradient gel (Invitrogen, Thermo 
Fisher Scientific) and blotted onto a nitrocellulose membrane using the iBlot dry transfer system (Invitrogen, Thermo Fisher Scientific). Membrane was blocked using 5\% SureBlock (LubioScience) diluted in 1X PBS containing 0.1\% Tween-20 (PBST, Sigma Aldrich) for 30 minutes. Membranes were then incubated with primary antibodies diluted in 1\% SureBlock-PBST (POM1, POM2 as anti-PrP antibody, $300 \mathrm{ng} / \mathrm{mL}$ final concentration (Polymenidou et al., 2008), anti-Hnrnpk antibody (ab70492, 1:5000 diluted, Abcam, Cambridge, UK) overnight at $4{ }^{\circ} \mathrm{C}$ under shaking conditions. For detection, antimouse HRP or anti-rabbit HRP (Bio-Rad) was diluted 1:5000 in 1\% SureBlock-PBST. Imaging was done on LAS-3000 System (Fujifilm, Tokyo, Japan).

\section{Cerebellar slice culture experiments}

Animal experiments were performed in accordance with the Swiss Animal Protection law and under a permit issued by the Canton of Zurich (Nr: 236/2019). Cerebellar slices were prepared from 12-day-old Tga20 mouse pups according to our published protocol (Falsig and Aguzzi, 2008). Briefly, acutely dissected cerebella were embedded in $2 \%$ low melting point agarose and cut into $350-\mu \mathrm{m}$ thick sections with a Leica vibratome in ice-cold Gey's balanced salt solution (GBSS) supplemented with kynurenic acid and glucose. For prion infection, slices were exposed to $0.001 \%$ brain homogenate derived from terminally sick RML6 prion inoculated mice (or normal brain homogenate as control) for 1 hour at $4{ }^{\circ} \mathrm{C}$ on a shaker. After several washes, six to eight slices were put onto a Millicell-CM Biopore PTFE membrane insert (Merck Millipore) and cultured in an incubator on top of slice culture medium containing $50 \% \mathrm{vol} / \mathrm{vol} \mathrm{MEM}, 25 \% \mathrm{vol} / \mathrm{vol}$ basal medium Eagle, $25 \% \mathrm{vol} / \mathrm{vol}$ horse serum, $0.65 \% \mathrm{w} / \mathrm{vol}$ glucose, $1 \%$ $\mathrm{vol} / \mathrm{vol}$ penicillin/streptomycin and $1 \%$ Glutamax. Culture medium was changed three times per week. To treat the cultured slices with PSA, stock PSA solution prepared in DMSO was diluted into the culture medium with a final concentration of $1 \mu \mathrm{M}$. Culture medium with the same concentration of DMSO was used as control. Fresh PSA was supplied to the media and media was changed every two to three days for a total duration of one month. At the end of the experiments, cultured slices were collected into the RIPA buffer and homogenized. Protein concentrations in the lysates were quantified using the BCA method. To detect prions by western blotting, lysates containing $50 \mu \mathrm{g}$ total proteins were mixed with proteinase $\mathrm{K}$ (with a final concentration of $20 \mu \mathrm{g} / \mathrm{mL}$ ) in a reaction volume of $30 \mu \mathrm{L}$ and incubated at 37 ${ }^{\circ} \mathrm{C}$ for 30 minutes. After mixing each digested sample with $10 \mu \mathrm{l} 4 \mathrm{X}$ loading buffer and boiled at $95{ }^{\circ} \mathrm{C}$ for 5 minutes, $18 \mu \mathrm{L}$ of each sample was loaded onto the gel for western blotting. Quantification was 
done using ImageJ software and results were plotted using GraphPad Prism8. To assess statistical significance an unpaired Student's t-test was performed.

SCEPA for detection of infectivity in PK and PIPLC treated cells

For assessing whether prion infectivity is intact after treatment with PK (Roche) or PIPLC (Thermo Fisher Scientific) 100.000 RML CAD5 cells were seeded in $2 \mathrm{~mL}$ of full culture media and grown to confluency for four days. Later, samples for PIPLC were treated with $0.1 \mathrm{U} / \mathrm{mL}$ of the enzyme which was spiked into the media and placed back in the incubator for one hour. Cells were then harvested in 1X PBS, centrifuged at $1500 \mathrm{XG}$ for 5 minutes for pelleting and finally the PBS was aspirated. $40 \mu \mathrm{L}$ 1X PBS was added to the cell pellet and lysis of the contents of the tube was followed with 5 freeze-thaw cycles in liquid nitrogen with vortexing. Subsequently, the lysate was centrifuged at $1000 \mathrm{XG}$ for three minutes and supernatant amounting to $50 \mu \mathrm{L}$ was transferred to a new Eppendorf tube. For PK digestion, $10 \mu \mathrm{L}$ of $15 \mu \mathrm{g} / \mathrm{mL}$ PK was added to the cells and digestion followed for 30 minutes at $37{ }^{\circ} \mathrm{C}$. Digestion was stopped using $5 \mu \mathrm{L}$ of PMSF (Sigma Aldrich) (final concentration $2.3 \mathrm{mM}$ ) under the same conditions described in the screening section of the manuscript. Untreated lysates as well as PIPLC treated samples were harvested as described above and $15 \mu \mathrm{L}$ PBS was added to the samples to make up the same volume. SCEPA was performed as previously described (Sorce et al., 2020).

shRNA design, cloning, lentiviral vector preparation and transduction

Using NEBuilder HiFi DNA Assembly Cloning Kit (NEB \#E5520), eGFP coding sequence (Addgene \# 17397) was cloned into our Auto-TDP-43-HA LV transfer vector (Hruska-Plochan et al., 2021), replacing TDP-43-HA, making Auto-EGFP. Custom MHP_shRNA cassette was synthetized by GenScript so that human U6 promoter is directly followed by random sequence of 54bp flanked by Hindlll and Pacl restriction sites. TTTTTTT was used for efficient PolllI termination (Gao et al., 2018) and TGTGCTT for loop (Jensen et al., 2012). This cassette was then cloned into Auto-EGFP via HiFi assembly, upstream from TRE promoter, generating pSHE LV transfer vector.

HNRNPK transcript variant 5 (NM_001318186.2) was then used as an input sequence for shRNA design using the following algorithms: Broad Institute GPP Web Portal, Invitrogen BLOCK-iT ${ }^{\mathrm{TM}}$ RNAi Designer, Kay Lab siRNA/shRNA/Oligo Optimal Design tool and RNAinverse server of ViennaRNA Web Services. 5 highest-scoring target sequences per algorithm were kept and 2 final target sequences were selected using rational design following the standard rules for pre-miRNA-like shRNA design (Bofill-De Ros and Gu, 2016), including Dicer loop-counting rule (Gu et al., 2012). Q5 site directed mutagenesis (NEB \#E0554S) was used to clone the designed shRNAs into pSHE, substituting the random sequence of the 
original cassette, generating pSHE-shHNRNPKa and pSHE-shHNRNPKb LV transfer vectors. shRNA targeting the HaloTag sequence was then designed as a non-targeting shRNA control and was cloned into pSHE as decribed above, generating pSHE-shHaloTag.

pSHE vectors were then packaged into lentivirus (LV) as described previously (Hruska-Plochan et al., 2021). The resulting lentiviral pellets were then resuspended in PBS to achieve 10x concentrated LV preparations, which were titrated using Lenti- $X^{\mathrm{TM}}$ GoStix ${ }^{\mathrm{TM}}$ Plus (Takara \#631280). 10x concentrate of pSHE LVs was then used at $300 \mathrm{ng}$ (of lentiviral p24 protein as per GoStix Value (GV)) per well of a 6 well plate of hovS cells pipetting the LV concentrate directly onto the culture (dropwise). Spent hovS media was then added to reach $1000 \mu$ l total. Medium was exchanged completely the following day.

HNRNPK knockdown efficacy of pSHE-shHNRNPKa and pSHE-shHNRNPKb was assessed in SHSY5Y cells and pSHE-shHNRNPKa was selected for hovS experiments. For immunoblotting of transduced cells, see above.

Primer list: shHNRNPKa $F$

5'-TGCTTAAGCATTCCA-'CAGCATCTTTTTTTAATTAACATGGTCCCAGC-3' ShHNRNPKa R 5'-AGCACAGCTTAAGCATTCCACAGCATCAAGCTTTCGTCCTTTCCAC-3' ShHNRNPKb $F$ 5'-TGCTTAAĀCCACCAACAATAACTTTTTTTAATTAACATGGTCCCAGC-3' ShHNRNPKb R 5'-AGCACAGCTTAAACCACCAACAATAACAAGCTTTCGTCCTTTCCAC-3' shHaloTag_F

5'-TGCTAAATGCAATACCTTTGACTTTTTTTAATTAACATGGTCCCAGC-3' shHaloTag $R$ 5'-AGCACAGCTAAATGCAATACCTTTGACAAGCTTTCGTCCTTTCCAC-3'

\section{RT-QulC assay}

The reaction buffer of the RT-QuIC consisted of $1 \mathrm{mM}$ EDTA (Life Technologies), $10 \mu \mathrm{M}$ thioflavin T, $170 \mathrm{mM} \mathrm{NaCl}$, and 1× PBS (incl. $130 \mathrm{mM} \mathrm{NaCl}$ ) and HaPrP23-231 filtered using 100-kD centrifugal filters (Pall Nanosep OD100C34) at a concentration of $0.1 \mathrm{mg} / \mathrm{ml}$. Fly brain homogenates were diluted in PBS and $2 \mu \mathrm{l}$ of the diluted homogenates were used to assess seeding activity, resuspended in 98ul of assay buffer in a 96-well plate format. The plate was loaded into a FLUOstar Omega plate reader (BMG Labtech) and the shaking cycles were set as follows: 7× (90 s shaking; 900 rpm [double orbital]; $30 \mathrm{~s}$ rest) and $60 \mathrm{~s}$ reading. Reading was carried out with excitation at $450 \mathrm{~nm}$ and emission at $480 \mathrm{~nm}$ every $15 \mathrm{~min}$. The amplification was performed at $42^{\circ} \mathrm{C}$ for $105 \mathrm{~h}$. Four replicates per sample were measured. Lag time was determined as timepoint at which the sample reached 20 '000 RFU.

Fly stocks

The UAS-PrP fly line w; $\quad M\{V R Q-P r P(G P I), \quad 3 x P 3-R F P . a t t P\} Z H-51 D \quad$ transgenic for $V^{136} R^{154} Q^{171}(V R Q)$ ovine PrP, expressed with an N-terminal leader peptide and C-terminal GPI signal 
bioRxiv preprint doi: https://doi.org/10.1101/2022.03.03.482765; this version posted March 4, 2022. The copyright holder for this preprint

(which was not certified by peer review) is the author/funder, who has granted bioRxiv a license to display the preprint in perpetuity. It is made available under aCC-BY-ND 4.0 International license.

sequence, was generated by PhiC31 site-specific transformation (Thackray et al., 2012) with Cremediated removal of the red fluorescent protein (RFP) as described previously (Thackray et al., 2014). The Elav-GAL4(P\{w[+mW.hs]=GawB\}elav[C155]) pan neuronal driver fly line was obtained from the Department of Genetics, University of Cambridge, UK. Drosophila were raised on standard cornmeal media at $25^{\circ} \mathrm{C}$ and maintained at low to medium density.

PSA treatment and prion inoculation of Drosophila

PSA was prepared in DMSO to give $0 \mathrm{mM}, 0.5 \mathrm{mM}, 0.75 \mathrm{mM}$ or $1 \mathrm{mM}$ final concentration of drug. Two hundred microlitres of the relevant dilution of PSA or DMSO alone were added to the top of fly feed in 3-inch plastic vials and the feed allowed to dry for 24 hours prior to use. A cross between the UASPrP fly line and the Elav-GAL4 driver fly line was set up in each of the drug-treated or control fly food vials described above. The parental flies were removed from the vials once first instar larvae were evident. For prion inoculation, $250 \mu \mathrm{L}$ of $1 \%$ (w/v) PG127 scrapie-positive sheep brain homogenate (Andréoletti et al., 2011)prepared in PBS pH 7.4, were added to drug-treated third instar VRQ ovine PrP Drosophila larvae. Following eclosion (i.e. hatching), flies were collected that were transgenic for VRQ ovine PrP expressed pan neuronally and were transferred to fresh drug-treated vials every other day for the duration of the study (40 days). The locomotor ability of flies was assessed in a negative geotaxis climbing assay as previously described (Thackray et al., 2018). Drosophila head homogenate was prepared from 5 and 40 day old flies as previously described (Thackray et al., 2018) and subjected to RT-QulC analysis as described in the materials and methods. Statistical analysis of the negative geotaxis climbing assay data was performed by the unpaired $t$-test, using Prism (GraphPad Software Inc, San Diego, USA). 


\section{Supplementary Figure 1. QUIPPER assay, Example plate maps}

A) Western Blot analysis of chronically RML6-infected CAD5 cells following PK digestion. Anti-PrP antibody POM1 is used for probing the membrane. Brain homogenates were used as controls. B) Western Blot analysis of chronically RML6-infected GT-1/7 cells after PK treatment. Membrane is probed with anti-PrP antibody POM1. Brain homogenates were used as controls. C) Plate map used in the screen depicting controls and samples. Light green represents wells containing siRNAs from the library, dark green represents wells containing Prnp-targeting control siRNAs and yellow represents wells containing non-targeting control siRNAs. D) Examples of heat maps for FRET as well as viability read-out from the primary screen. E) Schematic of the hit-selection process over all the screens performed in this study with the corresponding criteria.

Supplementary Figure 2. Secondary screen quality metrics and viability readout

A) Z'-factor for each plate of both deconvolution screens (for regulators of PrPPLC, top panel, for regulators of $\mathrm{PrP}^{\mathrm{C}}$, bottom panel) representing the robustness of the screens based on the separability of the positive (Prnp targeting) and negative (non-targeting) control B) Duplicate correlation of FRETdata for each screen. Coefficient of determination $\left(r^{2}\right.$-value $)$ is depicted in the graph. C) Duplicate correlation of viability-data measured using RealTime-Glo ${ }^{\mathrm{TM}}$ luminescence readout for each screen. Coefficient of determination ( $\mathrm{r}^{2}$-value) is depicted in the graph. D) Duplicates from C were averaged and normalized for each screen, and the two normalized values for each gene is correlated to assess if any gene regulates viability dependent on prion infection. The high $r^{2}$-value, as well as the lack of outliers demonstrates the lack of synthetic lethal genes in the subset assessed in the deconvolution screen.

Supplementary Figure 3. Prion strain dependence of the 97 candidates

A) Western Blot analysis of chronically $22 \mathrm{~L}$-infected GT-1/7 cells after PK treatment. Membrane is probed with anti-PrP antibody POM1. P4, P5 and P6 corresponds to the amount of passaging after exposure to 22L brain homogenate. Brain homogenates were used as controls. B) Correlation of the effect of 97 candidates on their effect on $\mathrm{PrP}^{\mathrm{Sc}}$ of two different prion strains (RML6 and 22L). Next to RML6 infected GT-1/7, 97 hits were assessed for their effect on 22L prion infected GT-1/7 for 72 hours as well as 96 hour-long treatment duration. The high coefficient of determination ( $r^{2}$-value) of the effect observed for both prion strains indicates that the candidates do not show strain-specificity.

Supplementary Figure 4. Phenotypic response of PG127prion infected hovS upon HNRNPK downregulation using siRNA or shRNA 
A) Brightfield microscopy images of the effect of siRNA and shRNA mediated HNRNPK downregulation on prion-induced vacuolation in PG127 hovS cells. The siRNA and shRNA mediated downregulation of HNRNPK in PG127 hovS leads to an enhanced cytopathological vacuolation phenotype when compared to NT siRNA or shRNA, corresponding to the increased level of prions seen in Fig. 4A and Supplementary Figure 4B. ovPRNP siRNA transfected, as well as uninfected cells were used as controls. Downregulation of ovPRNP in the infected hovS eliminates the vacuoles; HNRNPK downregulation in uninfected cells does not yield a vacuolation phenotype. Lower left panel: Quantification of vacuoles of NT, HNRNPK and ovPRNP siRNA treated PG127 hovS. Lower right panel: Quantification of vacuoles of NT and HNRNPK shRNA treated PG127 hovS. Cells from pictures at three different positions in the well were manually counted and the amount of vacuolated cells was normalized to the total amount of cells. Values represent mean \pm SD. ${ }^{*} p=0.0113,{ }^{* * *} p=0.0008,{ }^{* * *} p=<0.0001$ (Dunnett's multiple comparisons test). Scale bar $=100 \mu \mathrm{m}$ B) Western blot showing HNRNPK shRNA transduction (96 hrs.) decreases HNRNPK protein levels while increases PrPSc in PG127 prion infected hovS cells. $\alpha$ : anti. C) Western Blot analysis of the effect of PSA treatment on $\operatorname{PrP}^{\mathrm{C}}$ levels in uninfected GT-1/7 as well as hovS cells. PSA treatment does not affect the levels of $\operatorname{PrP}^{\mathrm{C}}$ when compared to untreated or DMSO treated cells. D) Western Blot analysis of the effect of PSA treatment on PrPSc and HNRNPK levels in PG127 prion infected hovS cells following transduction of control (NT) or HNRNPK targeting shRNAs. PSA treatment does not affect the levels of HNRNPK (upper panel) when compared to DMSO treated cells. The antiprion effect of PSA is limited upon silencing of HNRNPK (lower panel). $\alpha$ : anti.

\section{Supplementary Table}

Tab 1: Z-scores and normalized viability values for each gene assessed in the deconvolution screen

Tab 2: RNA-Seq of RML prion infected GT-1/7

Tab 3: MAGMA and VEGAS scores for comparing the 161 candidates for which human orthologues are available to a sCJD GWAS dataset.

Tab 4: Z-scores and normalized viability values for the 40 shortlisted genes assessed in the PrPsc screen, using PK readout after 72 hours and 96 hours of treatment, as well as their corresponding gene symbols for Homo sapiens.

Tab 5.1: RNAseq data of Hnrnpk downregulated RML GT-1/7 cells

Tab 5.2: RNAseq data of $1 \mu \mathrm{M}$ PSA treated RML GT-1/7 cells 


\section{Acknowledgements}

AA is the recipient of an Advanced Grant of the European Research Council and grants from the Swiss National Research Foundation, the Nomis Foundation, the Swiss Personalized Health Network (SPHN, 2017DRI17), and a donation from the estate of Dr. Hans Salvisberg. We would like to thank Dr. Emilio Yangüez and Dr. Maria Domenica Moccia and the Functional Genomics Center Zurich (FGCZ) for their help with the RNA-Sequencing experiment. We thank Dr. M. Ryan and Dr. O.H. Griffith for providing us with the expression system for B. cereus PIPLC. We thank Prof. Simon Mead for help with the analysis of the SCJD dataset. We thank Prof. Robert Kalb and Dr. Marco Boccitto for insightful discussions. In addition, we wholeheartedly thank Irina Abakumova and Rita Moos for their technical help. Summary Fig. 1A depicting the QUIPPER assay and Supplementary Fig. 1C have been created with BioRender.

\section{Author contributions}

Conceived and designed the experiments: MA, DH, AA. Supervised the study: SH, MP, RB, AA. Contributions to experimental work; siRNA primary and counter-screens: MA, DH, siRNA reformatting: MA, DH, DP, ME, bioinformatics: MA, DH, ES, AC, PSA experiments: MA, DH, SS, proposed the QUIPPER assay: AKKL, PIPLC purification: SH, shRNA design, production and validation: MHP, shRNA experiments in hovS: MA, DH, RNA-Seq experiment: MA, DH, COCS experiments and data analysis: YL, provided reagents and experimental help: JAY, ML. Drosophila melanogaster experiments and data analysis: MA, DH, AT, RB. Wrote the paper: MA, DH, AA. 


\section{References}

Aguzzi, A., and Calella, A.M. (2009). Prions: protein aggregation and infectious diseases. Physiol Rev 89, 1105-1152.

Andréoletti, O., Orge, L., Benestad, S.L., Beringue, V., Litaise, C., Simon, S., Le Dur, A., Laude, H., Simmons, H., Lugan, S., et al. (2011). Atypical/Nor98 scrapie infectivity in sheep peripheral tissues. PLoS Pathog 7, e1001285.

Atarashi, R., Sano, K., Satoh, K., and Nishida, N. (2011). Real-time quaking-induced conversion: a highly sensitive assay for prion detection. Prion 5, 150-153.

Avar, M., Heinzer, D., Steinke, N., Doğançay, B., Moos, R., Lugan, S., Cosenza, C., Hornemann, S., Andréoletti, O., and Aguzzi, A. (2020). Prion infection, transmission, and cytopathology modeled in a low-biohazard human cell line. Life Sci Alliance 3.

Bai, N., Hayashi, H., Aida, T., Namekata, K., Harada, T., Mishina, M., and Tanaka, K. (2013). Dock3 interaction with a glutamate-receptor NR2D subunit protects neurons from excitotoxicity. Mol Brain 6 , 22.

Ballmer, B.A., Moos, R., Liberali, P., Pelkmans, L., Hornemann, S., and Aguzzi, A. (2017). Modifiers of prion protein biogenesis and recycling identified by a highly parallel endocytosis kinetics assay. $\mathrm{J}$ Biol Chem 292, 8356-8368.

Bampton, A., Gatt, A., Humphrey, J., Cappelli, S., Bhattacharya, D., Foti, S., Brown, A.L., Asi, Y., Low, Y.H., Foiani, M., et al. (2021). HnRNP K mislocalisation is a novel protein pathology of frontotemporal lobar degeneration and ageing and leads to cryptic splicing. Acta Neuropathol 142, 609-627.

Banerjee, M., Datta, M., and Bhattacharyya, N.P. (2017). Modulation of mutant Huntingtin aggregates and toxicity by human myeloid leukemia factors. Int J Biochem Cell Biol 82, 1-9.

Bellingham, S.A., Coleman, L.A., Masters, C.L., Camakaris, J., and Hill, A.F. (2009). Regulation of prion gene expression by transcription factors SP1 and metal transcription factor-1. J Biol Chem 284, 12911301.

Bendheim, P.E., Barry, R.A., DeArmond, S.J., Stites, D.P., and Prusiner, S.B. (1984). Antibodies to a scrapie prion protein. Nature 310, 418-421.

Birmingham, A., Selfors, L.M., Forster, T., Wrobel, D., Kennedy, C.J., Shanks, E., Santoyo-Lopez, J., Dunican, D.J., Long, A., Kelleher, D., et al. (2009). Statistical methods for analysis of high-throughput RNA interference screens. Nat Methods 6, 569-575.

Boccitto, M., Lee, N., Sakamoto, S., Spruce, L.A., Handa, H., Clardy, J., Seeholzer, S.H., and Kalb, R.G. (2017). The Neuroprotective Marine Compound Psammaplysene A Binds the RNA-Binding Protein HNRNPK. Mar Drugs 15.

Bofill-De Ros, X., and Gu, S. (2016). Guidelines for the optimal design of miRNA-based shRNAs. Methods 103, 157-166.

Bolton, D.C., McKinley, M.P., and Prusiner, S.B. (1982). Identification of a protein that purifies with the scrapie prion. Science 218, 1309-1311.

Borchelt, D.R., Rogers, M., Stahl, N., Telling, G., and Prusiner, S.B. (1993). Release of the cellular prion protein from cultured cells after loss of its glycoinositol phospholipid anchor. Glycobiology 3, 319-329.

Caminati, G., and Procacci, P. (2020). Mounting evidence of FKBP12 implication in neurodegeneration. Neural Regen Res 15, 2195-2202.

Chen, Q., Kimura, H., and Schubert, D. (2002). A novel mechanism for the regulation of amyloid precursor protein metabolism. J Cell Biol 158, 79-89.

Chen, Q., Peto, C.A., Shelton, G.D., Mizisin, A., Sawchenko, P.E., and Schubert, D. (2009). Loss of modifier of cell adhesion reveals a pathway leading to axonal degeneration. J Neurosci 29, 118-130.

Chen, Q., Yoshida, H., Schubert, D., Maher, P., Mallory, M., and Masliah, E. (2001). Presenilin binding protein is associated with neurofibrillary alterations in Alzheimer's disease and stimulates tau phosphorylation. Am J Pathol 159, 1597-1602.

Deleault, N.R., Lucassen, R.W., and Supattapone, S. (2003). RNA molecules stimulate prion protein conversion. Nature 425, 717-720.

Deleault, N.R., Piro, J.R., Walsh, D.J., Wang, F., Ma, J., Geoghegan, J.C., and Supattapone, S. (2012a). Isolation of phosphatidylethanolamine as a solitary cofactor for prion formation in the absence of nucleic acids. Proc Natl Acad Sci U S A 109, 8546-8551.

Deleault, N.R., Walsh, D.J., Piro, J.R., Wang, F., Wang, X., Ma, J., Rees, J.R., and Supattapone, S. (2012b). Cofactor molecules maintain infectious conformation and restrict strain properties in purified prions. Proc Natl Acad Sci U S A 109, E1938-1946.

Dery, M.A., Jodoin, J., Ursini-Siegel, J., Aleynikova, O., Ferrario, C., Hassan, S., Basik, M., and LeBlanc, A.C. (2013). Endoplasmic reticulum stress induces PRNP prion protein gene expression in breast cancer. Breast Cancer Res 15, R22. 
Dorweiler, J.E., Oddo, M.J., Lyke, D.R., Reilly, J.A., Wisniewski, B.T., Davis, E.E., Kuborn, A.M., Merrill, S.J., and Manogaran, A.L. (2020). The actin cytoskeletal network plays a role in yeast prion transmission and contributes to prion stability. Mol Microbiol 114, 480-494.

Enari, M., Flechsig, E., and Weissmann, C. (2001). Scrapie prion protein accumulation by scrapieinfected neuroblastoma cells abrogated by exposure to a prion protein antibody. Proc Natl Acad Sci $U$ S A 98, 9295-9299.

Falsig, J., and Aguzzi, A. (2008). The prion organotypic slice culture assay--POSCA. Nat Protoc 3, 555562.

Gao, Z., Herrera-Carrillo, E., and Berkhout, B. (2018). Delineation of the Exact Transcription Termination Signal for Type 3 Polymerase III. Mol Ther Nucleic Acids 10, 36-44.

Ghaemmaghami, S., May, B.C., Renslo, A.R., and Prusiner, S.B. (2010). Discovery of 2-aminothiazoles as potent antiprion compounds. J Virol 84, 3408-3412.

Giorgini, F., Guidetti, P., Nguyen, Q., Bennett, S.C., and Muchowski, P.J. (2005). A genomic screen in yeast implicates kynurenine 3-monooxygenase as a therapeutic target for Huntington disease. Nat Genet 37, 526-531.

Gu, S., Jin, L., Zhang, Y., Huang, Y., Zhang, F., Valdmanis, P.N., and Kay, M.A. (2012). The loop position of shRNAs and pre-miRNAs is critical for the accuracy of dicer processing in vivo. Cell 151, 900-911.

Hatakeyama, M., Opitz, L., Russo, G., Qi, W., Schlapbach, R., and Rehrauer, H. (2016). SUSHI: an exquisite recipe for fully documented, reproducible and reusable NGS data analysis. BMC Bioinformatics 17, 228.

Heinz, D.W., Ryan, M., Bullock, T.L., and Griffith, O.H. (1995). Crystal structure of the phosphatidylinositol-specific phospholipase $\mathrm{C}$ from Bacillus cereus in complex with myo-inositol. EMBO J 14, 3855-3863.

Heinzer, D., Avar, M., Pease, D.P., Dhingra, A., Yin, J.A., Schaper, E., Doğançay, B., Emmenegger, M., Spinelli, A., Maggi, K., et al. (2021). Novel regulators of PrPC biosynthesis revealed by genome-wide RNA interference. PLoS Pathog 17, e1010013.

Hornemann, S., Schorn, C., and Wüthrich, K. (2004). NMR structure of the bovine prion protein isolated from healthy calf brains. EMBO Rep 5, 1159-1164.

Hruska-Plochan, M., Betz, K.M., Ronchi, S., Wiersma, V.I., Maniecka, Z., Hock, E.-M., Laferriere, F., Sahadevan, S., Hoop, V., Delvendahl, I., et al. (2021). Human neural networks with sparse TDP-43 pathology reveal NPTX2 misregulation in ALS/FTLD. bioRxiv, 2021.2012.2008.471089.

Jansen, I.E., Savage, J.E., Watanabe, K., Bryois, J., Williams, D.M., Steinberg, S., Sealock, J., Karlsson, I.K., Hägg, S., Athanasiu, L., et al. (2019). Genome-wide meta-analysis identifies new loci and functional pathways influencing Alzheimer's disease risk. Nat Genet 51, 404-413.

Jensen, S.M., Schmitz, A., Pedersen, F.S., Kjems, J., and Bramsen, J.B. (2012). Functional selection of shRNA loops from randomized retroviral libraries. PLoS One 7, e43095.

Jones, E., Hummerich, H., Viré, E., Uphill, J., Dimitriadis, A., Speedy, H., Campbell, T., Norsworthy, P., Quinn, L., Whitfield, J., et al. (2020). Identification of novel risk loci and causal insights for sporadic Creutzfeldt-Jakob disease: a genome-wide association study. Lancet Neurol 19, 840-848.

Kampmann, M. (2018). CRISPRi and CRISPRa Screens in Mammalian Cells for Precision Biology and Medicine. ACS Chem Biol 13, 406-416.

Klein, M.A., Frigg, R., Flechsig, E., Raeber, A.J., Kalinke, U., Bluethmann, H., Bootz, F., Suter, M., Zinkernagel, R.M., and Aguzzi, A. (1997). A crucial role for B cells in neuroinvasive scrapie. Nature 390, 687-690.

Klöhn, P.C., Stoltze, L., Flechsig, E., Enari, M., and Weissmann, C. (2003). A quantitative, highly sensitive cell-based infectivity assay for mouse scrapie prions. Proc Natl Acad Sci U S A 100, 1166611671.

Knowles, T.P.J., Waudby, C.A., Devlin, G.L., Cohen, S.I.A., Aguzzi, A., Vendruscolo, M., Terentjev, E.M., Welland, M.E., and Dobson, C.M. (2009). An Analytical Solution to the Kinetics of Breakable Filament Assembly. Science 326, 1533-1537.

Li, B. (2016). Establishment of An Automated Digital Prion Infectivity Cell Assay and PrP-HPFRET Based High-throughput siRNA Screening Platform.

Lloyd, S.E., Mead, S., and Collinge, J. (2013). Genetics of prion diseases. Curr Opin Genet Dev 23, 345-351.

Ma, J., and Lindquist, S. (2001). Wild-type PrP and a mutant associated with prion disease are subject to retrograde transport and proteasome degradation. Proc Natl Acad Sci U S A 98, 14955-14960.

Ma, J.Y., and Lindquist, S. (2002). Conversion of PrP to a self-perpetuating PrPSc-like conformation in the cytosol. Science 298, 1785-1788.

Ma, J.Y., Wollmann, R., and Lindquist, S. (2002). Neurotoxicity and neurodegeneration when PrP accumulates in the cytosol. Science $298,1781-1785$. 
Mahal, S.P., Demczyk, C.A., Smith, E.W., Jr., Klohn, P.C., and Weissmann, C. (2008). Assaying prions in cell culture: the standard scrapie cell assay (SSCA) and the scrapie cell assay in end point format (SCEPA). Methods Mol Biol 459, 49-68.

Marbiah, M.M., Harvey, A., West, B.T., Louzolo, A., Banerjee, P., Alden, J., Grigoriadis, A., Hummerich, H., Kan, H.M., Cai, Y., et al. (2014). Identification of a gene regulatory network associated with prion replication. EMBO J 33, 1527-1547.

McKinley, M.P., Bolton, D.C., and Prusiner, S.B. (1983). A protease-resistant protein is a structural component of the scrapie prion. Cell 35, 57-62.

Mead, S., Poulter, M., Uphill, J., Beck, J., Whitfield, J., Webb, T.E., Campbell, T., Adamson, G., Deriziotis, P., Tabrizi, S.J., et al. (2009). Genetic risk factors for variant Creutzfeldt-Jakob disease: a genome-wide association study. Lancet Neurol 8, 57-66.

Mead, S., Uphill, J., Beck, J., Poulter, M., Campbell, T., Lowe, J., Adamson, G., Hummerich, H., Klopp, N., Rückert, I.M., et al. (2012). Genome-wide association study in multiple human prion diseases suggests genetic risk factors additional to PRNP. Hum Mol Genet 21, 1897-1906.

Mellon, P.L., Windle, J.J., Goldsmith, P.C., Padula, C.A., Roberts, J.L., and Weiner, R.I. (1990). Immortalization of hypothalamic GnRH neurons by genetically targeted tumorigenesis. Neuron 5, 1-10. Mohr, S., Bakal, C., and Perrimon, N. (2010). Genomic screening with RNAi: results and challenges. Annu Rev Biochem 79, 37-64.

Moujalled, D., James, J.L., Yang, S., Zhang, K., Duncan, C., Moujalled, D.M., Parker, S.J., Caragounis, A., Lidgerwood, G., Turner, B.J., et al. (2015). Phosphorylation of hnRNP K by cyclin-dependent kinase 2 controls cytosolic accumulation of TDP-43. Hum Mol Genet 24, 1655-1669.

Nalls, M.A., Blauwendraat, C., Vallerga, C.L., Heilbron, K., Bandres-Ciga, S., Chang, D., Tan, M., Kia, D.A., Noyce, A.J., Xue, A., et al. (2019). Identification of novel risk loci, causal insights, and heritable risk for Parkinson's disease: a meta-analysis of genome-wide association studies. Lancet Neurol 18, 1091-1102.

Nuvolone, M., Aguzzi, A., and Heikenwalder, M. (2009). Cells and prions: a license to replicate. FEBS Lett 583, 2674-2684.

Oliveira da Silva, M.I., and Liz, M.A. (2020). Linking Alpha-Synuclein to the Actin Cytoskeleton: Consequences to Neuronal Function. Front Cell Dev Biol 8, 787.

Outeiro, T.F., and Lindquist, S. (2003). Yeast cells provide insight into alpha-synuclein biology and pathobiology. Science 302, 1772-1775.

Parkyn, C.J., Vermeulen, E.G., Mootoosamy, R.C., Sunyach, C., Jacobsen, C., Oxvig, C., Moestrup, S., Liu, Q., Bu, G., Jen, A., et al. (2008). LRP1 controls biosynthetic and endocytic trafficking of neuronal prion protein. J Cell Sci 121, 773-783.

Pease, D., Scheckel, C., Schaper, E., Eckhardt, V., Emmenegger, M., Xenarios, I., and Aguzzi, A. (2019). Genome-wide identification of microRNAs regulating the human prion protein. Brain Pathol 29, 232-244.

Peretz, D., Scott, M.R., Groth, D., Williamson, R.A., Burton, D.R., Cohen, F.E., and Prusiner, S.B. (2001). Strain-specified relative conformational stability of the scrapie prion protein. Protein Sci 10, 854863.

Polymenidou, M., Moos, R., Scott, M., Sigurdson, C., Shi, Y.Z., Yajima, B., Hafner-Bratkovic, I., Jerala, R., Hornemann, S., Wuthrich, K., et al. (2008). The POM monoclonals: a comprehensive set of antibodies to non-overlapping prion protein epitopes. PLoS One 3, e3872.

Prinz, M., Heikenwalder, M., Junt, T., Schwarz, P., Glatzel, M., Heppner, F.L., Fu, Y.X., Lipp, M., and Aguzzi, A. (2003). Positioning of follicular dendritic cells within the spleen controls prion neuroinvasion. Nature 425, 957-962.

Prusiner, S.B., Cochran, S.P., Groth, D.F., Downey, D.E., Bowman, K.A., and Martinez, H.M. (1982). Measurement of the scrapie agent using an incubation time interval assay. Ann Neurol 11, 353-358.

Raymond, G.J., Zhao, H.T., Race, B., Raymond, L.D., Williams, K., Swayze, E.E., Graffam, S., Le, J., Caron, T., Stathopoulos, J., et al. (2019). Antisense oligonucleotides extend survival of prion-infected mice. JCl Insight 5.

Rostami, J., Holmqvist, S., Lindström, V., Sigvardson, J., Westermark, G.T., Ingelsson, M., Bergström, J., Roybon, L., and Erlandsson, A. (2017). Human Astrocytes Transfer Aggregated Alpha-Synuclein via Tunneling Nanotubes. J Neurosci 37, 11835-11853.

Ryan, M., Smith, M.P., Vinod, T.K., Lau, W.L., Keana, J.F., and Griffith, O.H. (1996). Synthesis, structure-activity relationships, and the effect of polyethylene glycol on inhibitors of phosphatidylinositolspecific phospholipase C from Bacillus cereus. J Med Chem 39, 4366-4376.

Rybner, C., Hillion, J., Sahraoui, T., Lanotte, M., and Botti, J. (2002). All-trans retinoic acid downregulates prion protein expression independently of granulocyte maturation. Leukemia 16, 940-948.

Saborio, G.P., Permanne, B., and Soto, C. (2001). Sensitive detection of pathological prion protein by cyclic amplification of protein misfolding. Nature 411, 810-813. 
Sanchez-Juan, P., Bishop, M.T., Kovacs, G.G., Calero, M., Aulchenko, Y.S., Ladogana, A., Boyd, A., Lewis, V., Ponto, C., Calero, O., et al. (2014). A genome wide association study links glutamate receptor pathway to sporadic Creutzfeldt-Jakob disease risk. PLoS One 10, e0123654.

Schludi, M.H., Becker, L., Garrett, L., Gendron, T.F., Zhou, Q., Schreiber, F., Popper, B., Dimou, L., Strom, T.M., Winkelmann, J., et al. (2017). Spinal poly-GA inclusions in a C9orf72 mouse model trigger motor deficits and inflammation without neuron loss. Acta Neuropathol 134, 241-254.

Schneider, C.A., Rasband, W.S., and Eliceiri, K.W. (2012). NIH Image to ImageJ: 25 years of image analysis. Nat Methods 9, 671-675.

See, S.K., Chen, M., Bax, S., Tian, R., Woerman, A., Tse, E., Johnson, I.E., Nowotny, C., Muñoz, E.N., Sengstack, J., et al. (2021). PIKfyve inhibition blocks endolysosomal escape of a-synuclein fibrils and spread of $\alpha$-synuclein aggregation. bioRxiv, 2021.2001.2021.427704.

Shi, S., Mitteregger-Kretzschmar, G., Giese, A., and Kretzschmar, H.A. (2013). Establishing quantitative real-time quaking-induced conversion (qRT-QuIC) for highly sensitive detection and quantification of PrPSc in prion-infected tissues. Acta Neuropathol Commun 1, 44.

Shyu, W.C., Harn, H.J., Saeki, K., Kubosaki, A., Matsumoto, Y., Onodera, T., Chen, C.J., Hsu, Y.D., and Chiang, Y.H. (2002). Molecular modulation of expression of prion protein by heat shock. Mol Neurobiol 26, 1-12.

Sidhu, R., Gatt, A., Fratta, P., Lashley, T., and Bampton, A. (2022). HnRNP K mislocalisation in neurons of the dentate nucleus is a novel neuropathological feature of neurodegenerative disease and ageing. Neuropathol Appl Neurobiol.

Solassol, J., Crozet, C., and Lehmann, S. (2003). Prion propagation in cultured cells. Br Med Bull 66, 87-97.

Sorce, S., Nuvolone, M., Russo, G., Chincisan, A., Heinzer, D., Avar, M., Pfammatter, M., Schwarz, P., Delic, M., Müller, M., et al. (2020). Genome-wide transcriptomics identifies an early preclinical signature of prion infection. PLoS Pathog 16, e1008653.

Stahl, N., Borchelt, D.R., and Prusiner, S.B. (1990). Differential release of cellular and scrapie prion proteins from cellular membranes by phosphatidylinositol-specific phospholipase C. Biochemistry 29 , 5405-5412.

Stone, T.W., Ceruti, S., and Abbracchio, M.P. (2009). Adenosine receptors and neurological disease: neuroprotection and neurodegeneration. Handb Exp Pharmacol, 535-587.

Tachi, N., Hashimoto, Y., and Matsuoka, M. (2012). MOCA is an integrator of the neuronal death signals that are activated by familial Alzheimer's disease-related mutants of amyloid $\beta$ precursor protein and presenilins. Biochem J 442, 413-422.

Takano, M., Tashiro, E., Kitamura, A., Maita, H., Iguchi-Ariga, S.M., Kinjo, M., and Ariga, H. (2014). Prefoldin prevents aggregation of a-synuclein. Brain Res 1542, 186-194.

Taraboulos, A., Raeber, A.J., Borchelt, D.R., Serban, D., and Prusiner, S.B. (1992). Synthesis and trafficking of prion proteins in cultured cells. Mol Biol Cell 3, 851-863.

Taylor, R. (1990). Interpretation of the Correlation Coefficient: A Basic Review. Journal of Diagnostic Medical Sonography 6, 35-39.

Thackray, A.M., Andréoletti, O., and Bujdoso, R. (2018). Mammalian prion propagation in PrP transgenic Drosophila. Brain 141, 2700-2710.

Thackray, A.M., Di, Y., Zhang, C., Wolf, H., Pradl, L., Vorberg, I., Andréoletti, O., and Bujdoso, R. (2014). Prion-induced and spontaneous formation of transmissible toxicity in PrP transgenic Drosophila. Biochem J 463, 31-40.

Thackray, A.M., Muhammad, F., Zhang, C., Di, Y., Jahn, T.R., Landgraf, M., Crowther, D.C., Evers, J.F., and Bujdoso, R. (2012). Ovine PrP transgenic Drosophila show reduced locomotor activity and decreased survival. Biochem J 444, 487-495.

Tsherniak, A., Vazquez, F., Montgomery, P.G., Weir, B.A., Kryukov, G., Cowley, G.S., Gill, S., Harrington, W.F., Pantel, S., Krill-Burger, J.M., et al. (2017). Defining a Cancer Dependency Map. Cell 170, 564-576.e516.

Uhlén, M., Fagerberg, L., Hallström, B.M., Lindskog, C., Oksvold, P., Mardinoglu, A., Sivertsson, A., Kampf, C., Sjöstedt, E., Asplund, A., et al. (2015). Proteomics. Tissue-based map of the human proteome. Science 347, 1260419.

Vallabh, S.M., Minikel, E.V., Schreiber, S.L., and Lander, E.S. (2020). Towards a treatment for genetic prion disease: trials and biomarkers. Lancet Neurol 19, 361-368.

van Rheenen, W., Shatunov, A., Dekker, A.M., McLaughlin, R.L., Diekstra, F.P., Pulit, S.L., van der Spek, R.A., Võsa, U., de Jong, S., Robinson, M.R., et al. (2016). Genome-wide association analyses identify new risk variants and the genetic architecture of amyotrophic lateral sclerosis. Nat Genet 48 , 1043-1048.

Victoria, G.S., and Zurzolo, C. (2017). The spread of prion-like proteins by lysosomes and tunneling nanotubes: Implications for neurodegenerative diseases. J Cell Biol 216, 2633-2644. 
bioRxiv preprint doi: https://doi.org/10.1101/2022.03.03.482765; this version posted March 4. 2022. The copyright holder for this preprint (which was not certified by peer review) is the author/funder, who has granted bioRxiv a license to display the preprint in perpetuity. It is made available under aCC-BY-ND 4.0 International license.

Vincent, B., Sunyach, C., Orzechowski, H.D., St George-Hyslop, P., and Checler, F. (2009). p53Dependent transcriptional control of cellular prion by presenilins. J Neurosci 29, 6752-6760.

Wang, J., Vasaikar, S., Shi, Z., Greer, M., and Zhang, B. (2017). WebGestalt 2017: a more comprehensive, powerful, flexible and interactive gene set enrichment analysis toolkit. Nucleic Acids Res 45, W130-W137.

Wu, W., Zhao, D., Shah, S.Z.A., Zhang, X., Lai, M., Yang, D., Wu, X., Guan, Z., Li, J., Zhao, H., et al. (2019). OPA1 overexpression ameliorates mitochondrial cristae remodeling, mitochondrial dysfunction, and neuronal apoptosis in prion diseases. Cell Death Dis 10, 710.

Zhang, J.H., Chung, T.D., and Oldenburg, K.R. (1999). A Simple Statistical Parameter for Use in Evaluation and Validation of High Throughput Screening Assays. J Biomol Screen 4, 67-73.

Zhang, X.D. (2011). Illustration of SSMD, z score, SSMD*, $z^{*}$ score, and t statistic for hit selection in RNAi high-throughput screens. J Biomol Screen 16, 775-785. 


\section{bioRxiv preprint doi: $h$ ttps://doi.org/10.1101/2022.03.03.482765; this version posted March 4, 2022. The copyright holder for this preprint}

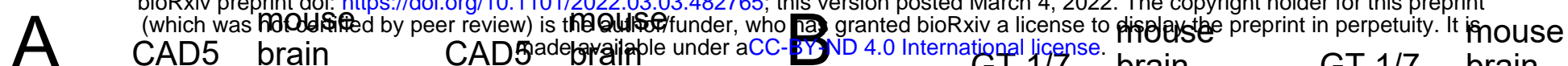

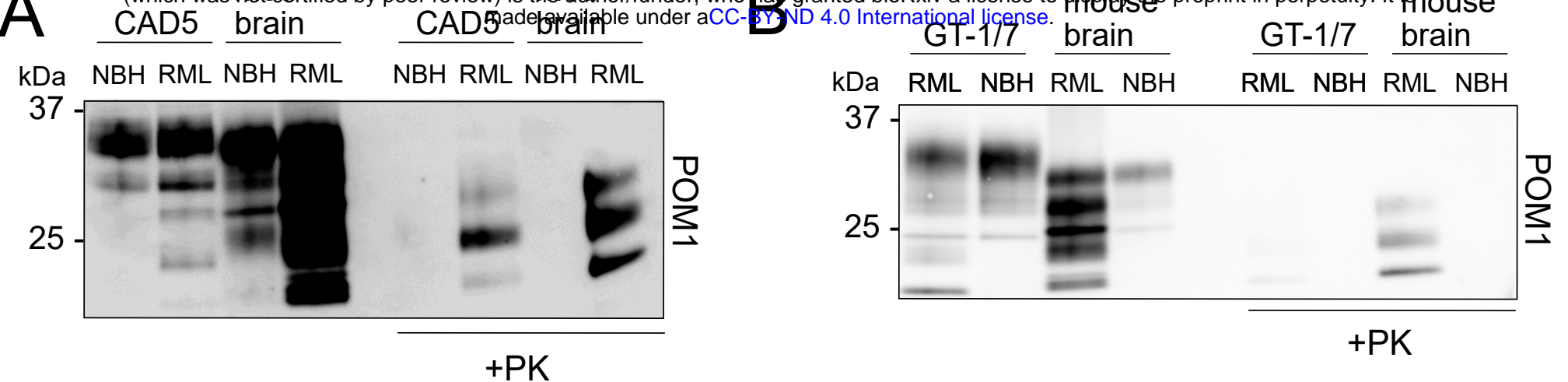

C
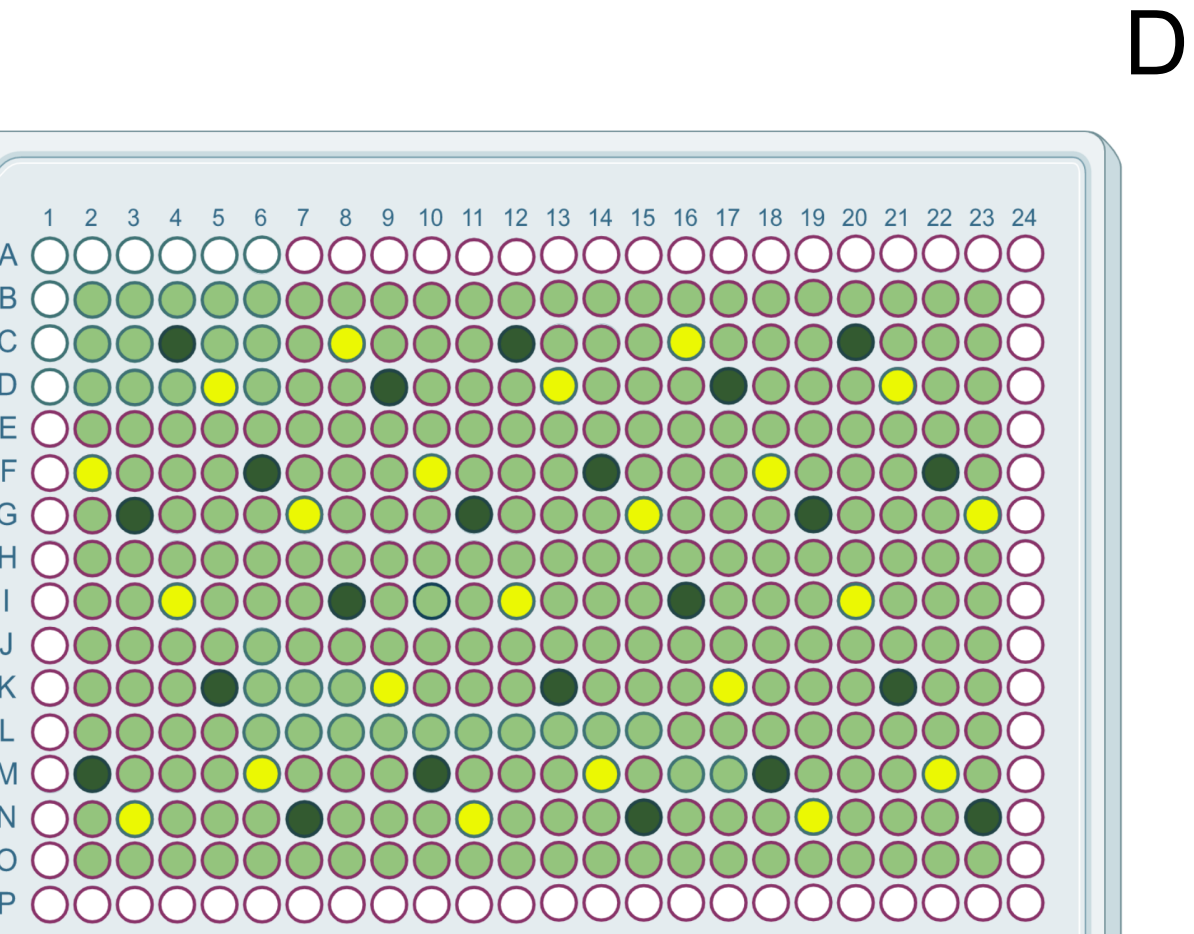

Heat Map FRET read-out

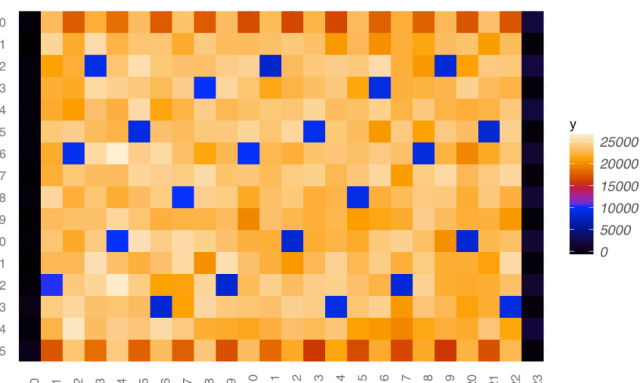

Heat Map RT-Glo read-out

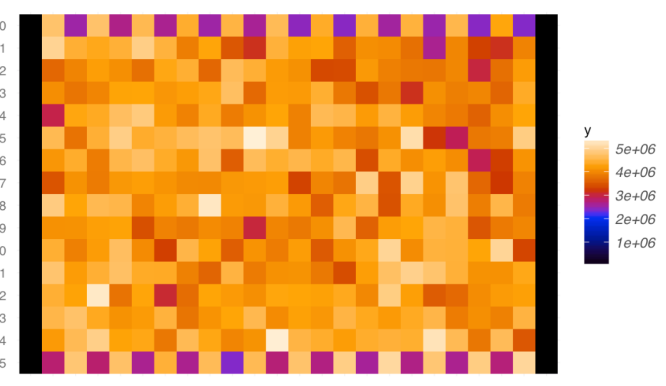

17‘582 genes - whole genome library

RML GT-1/7 - PrPPLC
standard score

$\leq-3.5$ or $\geq 3.5$

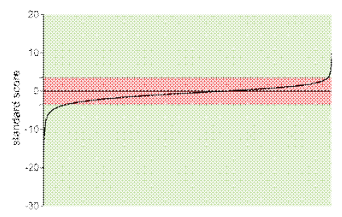

2'515 genes - primary candidates

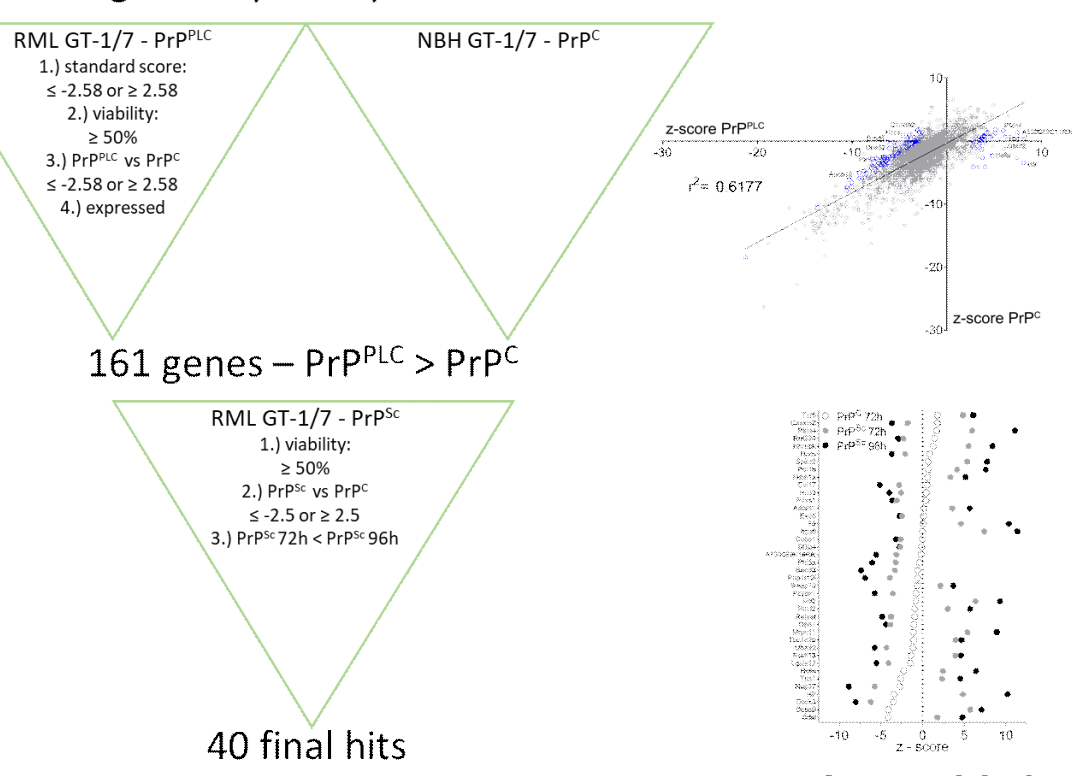

Avar, Heinzer et al., Supplementary Fig. 1 
bioRxiv preprint doi: https://doi.org/10.1101/2022.03.03.482765;

bioRxiv preprint doi: https://doi.org/10.1101/2022.03.03.482765; version posted March 4, 2022. The copyright holder for this preprint

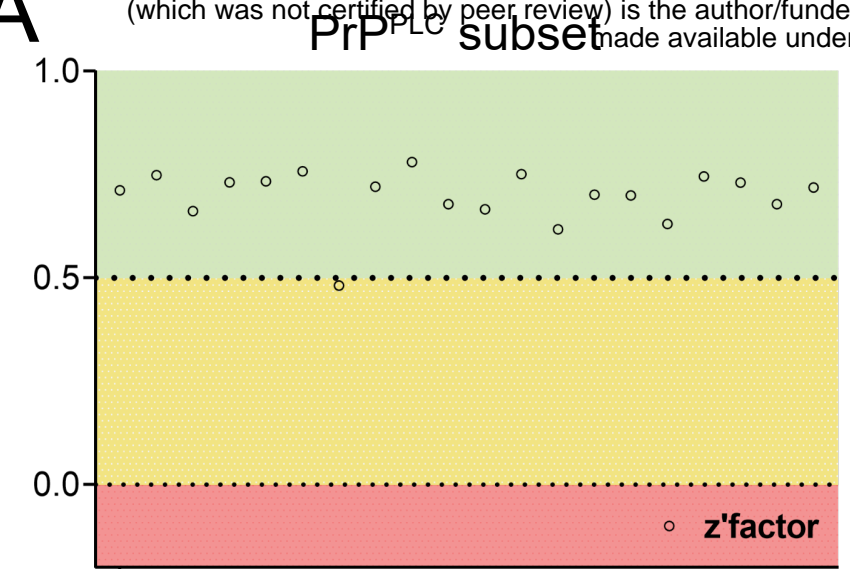
as granted bioRxiv a license tpdisplay the ereptibtin perpetuity. It is
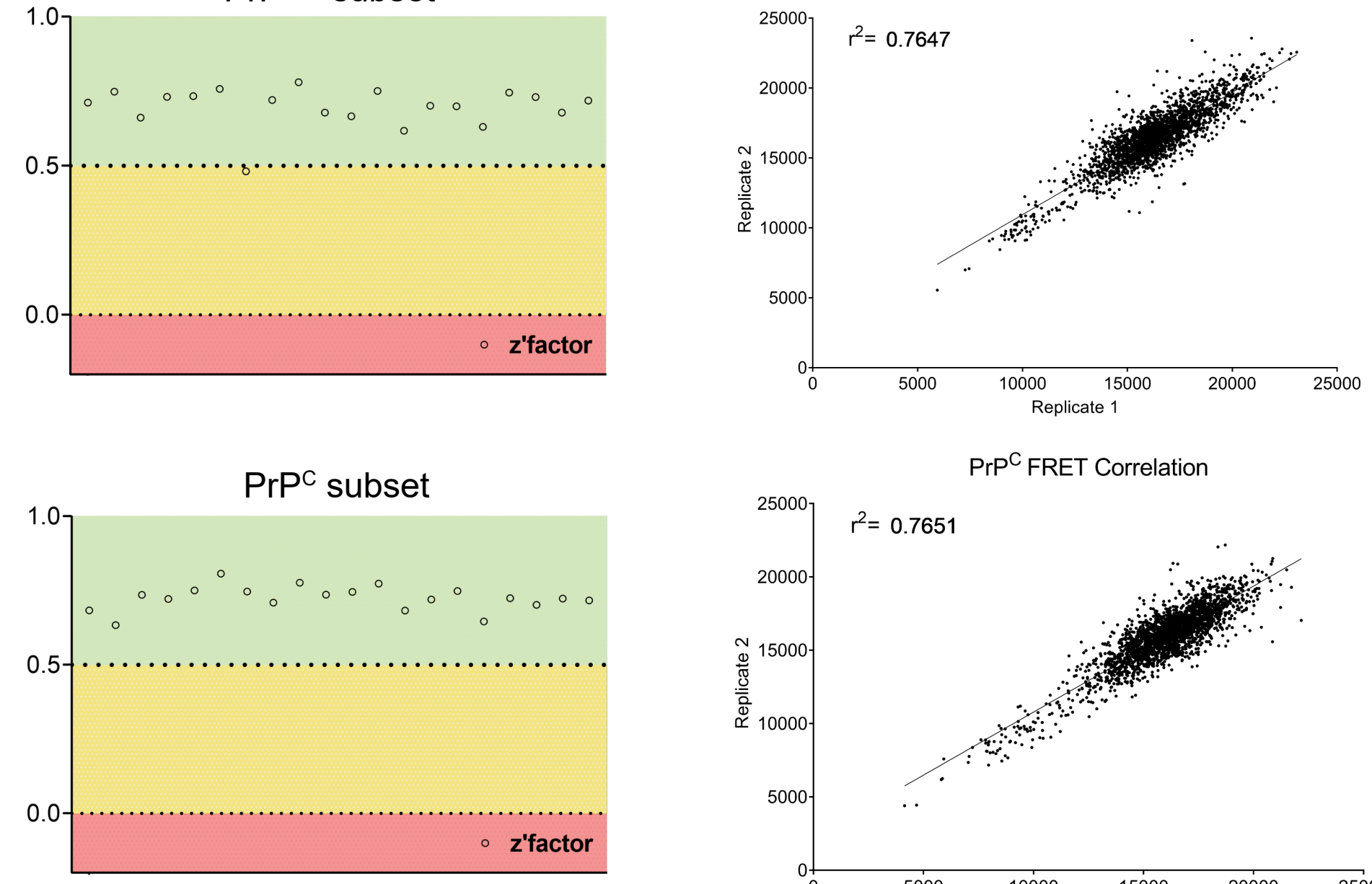

$\operatorname{PrP}^{\mathrm{C}}$ FRET Correlation

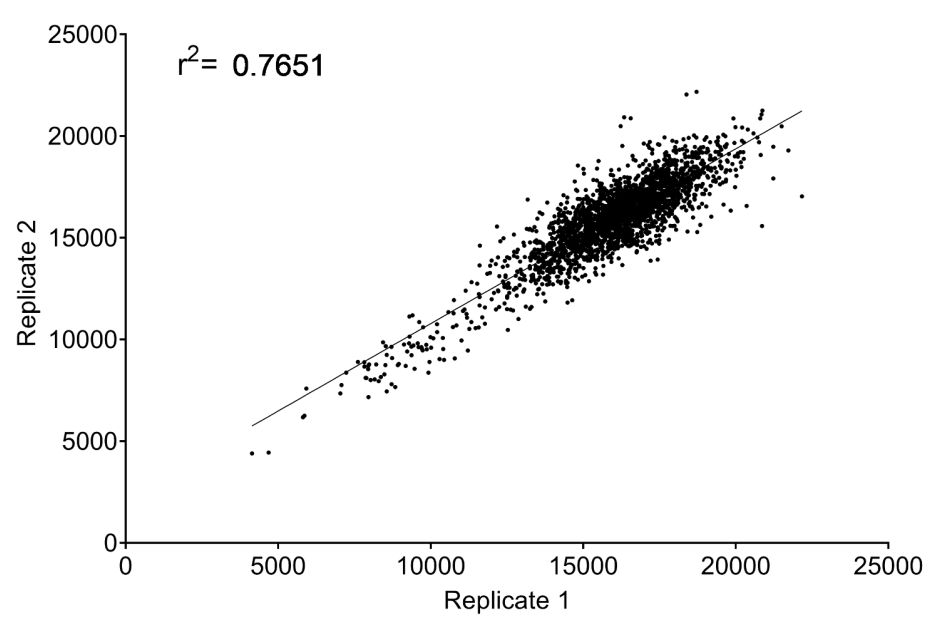

C

RT-Glo Correlation PrPPLC

D
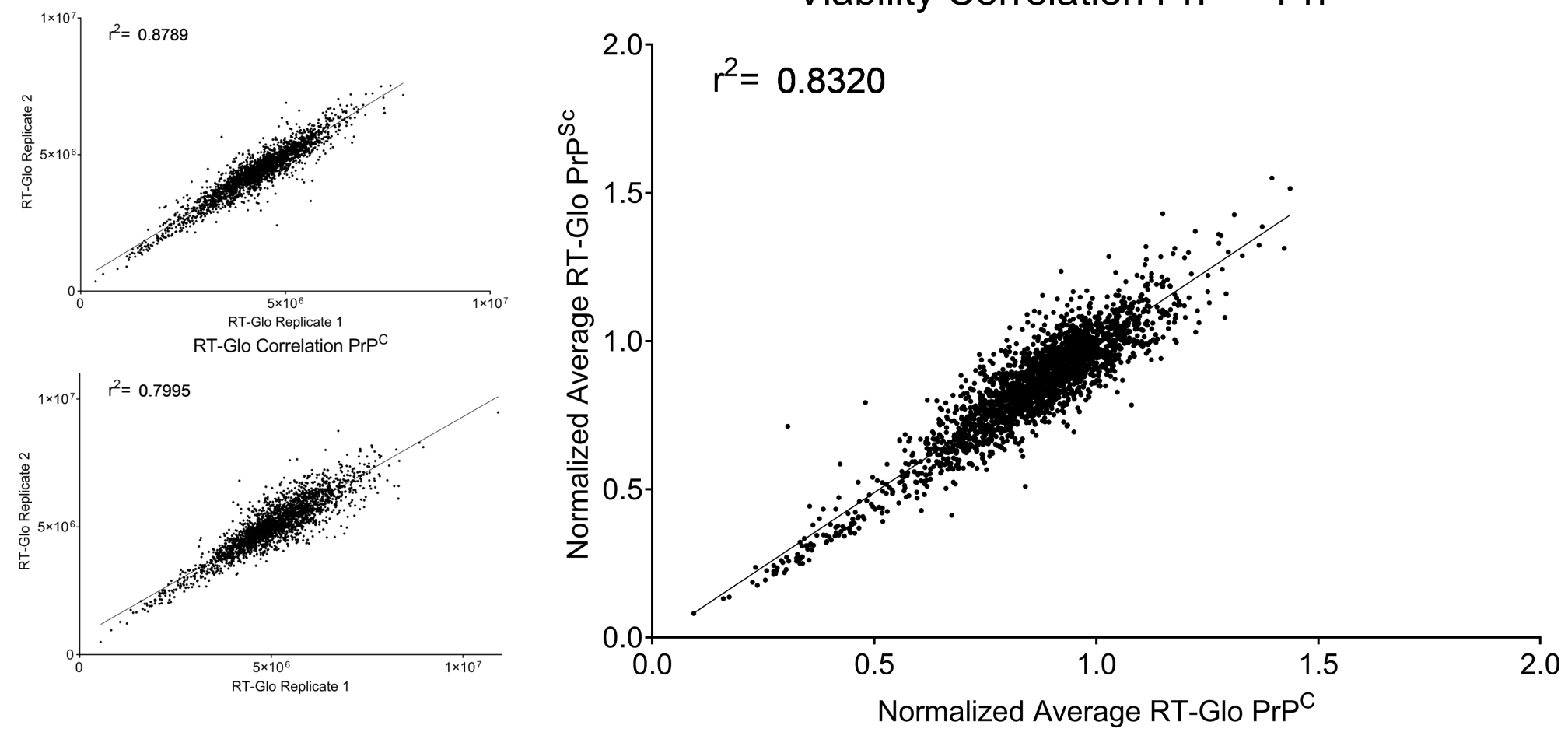

Avar, Heinzer et al., Supplementary Fig. 2 


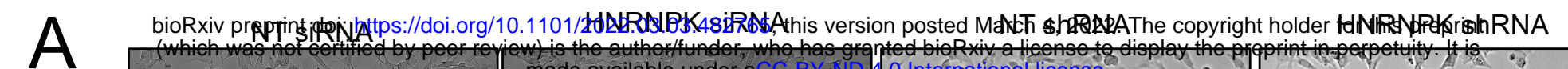

PG127

hovs

$\mathrm{NBH}$

hovS

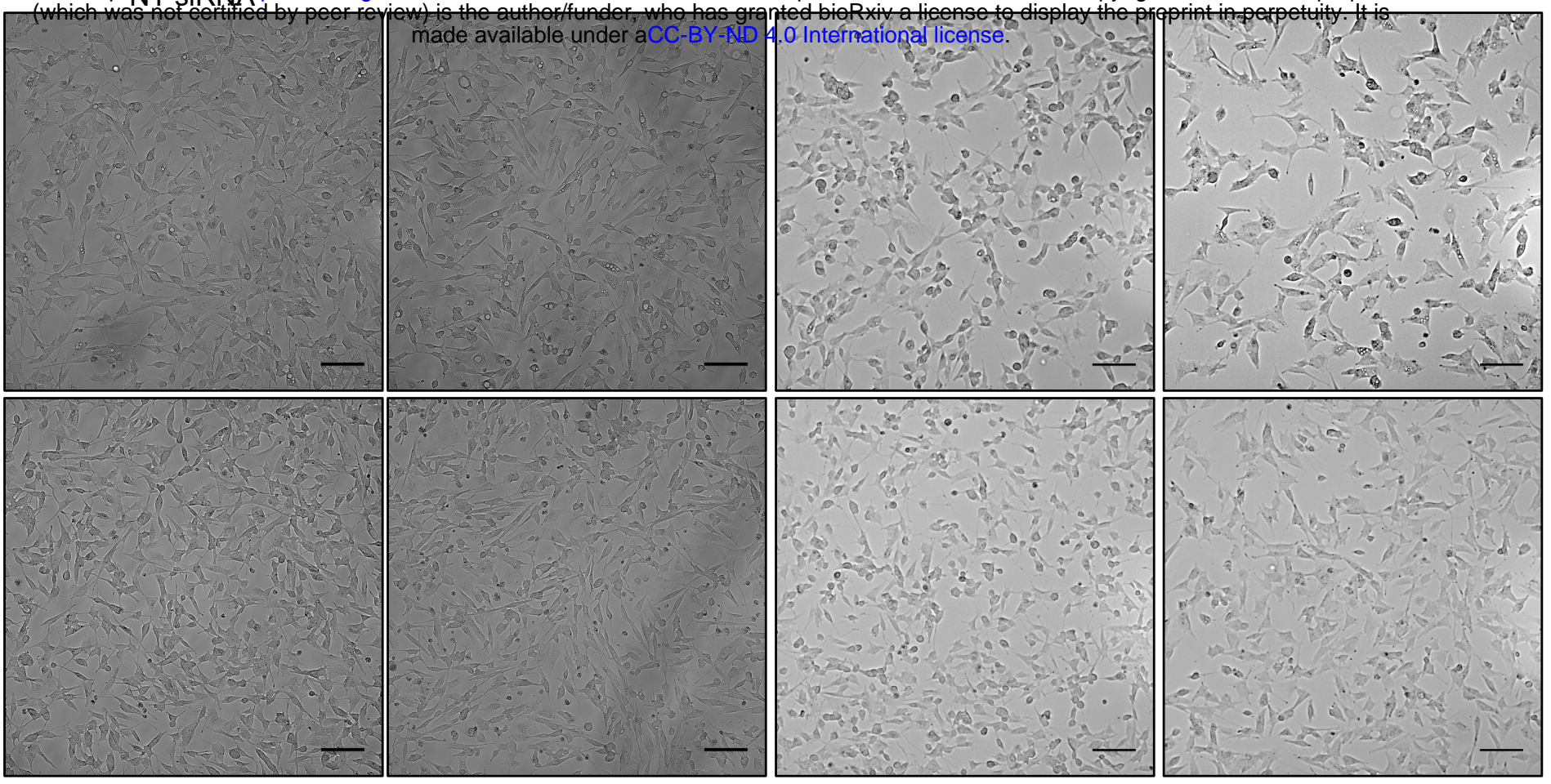

PG127

OVPRNP SiRNA

hovs
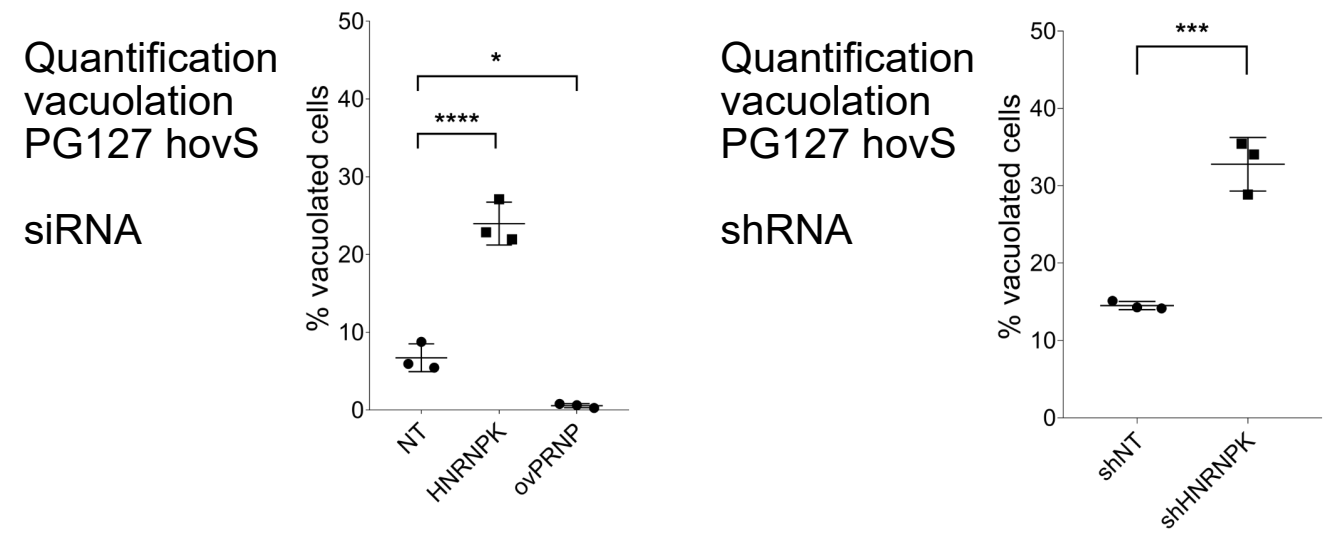

B

$\mathrm{NBH}$ hovS

\section{0
$4 !$
37
$2 !$}

Untreated $\quad$ shNT $\quad$ shHNRNPK
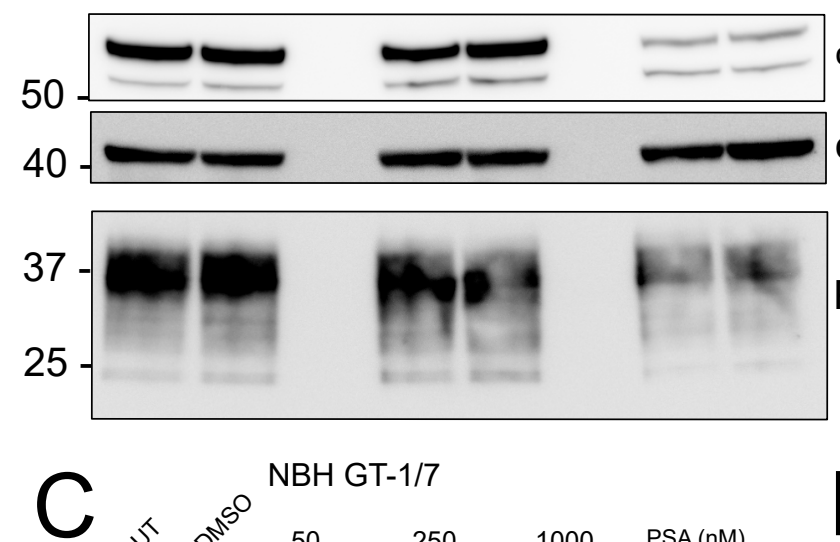

37
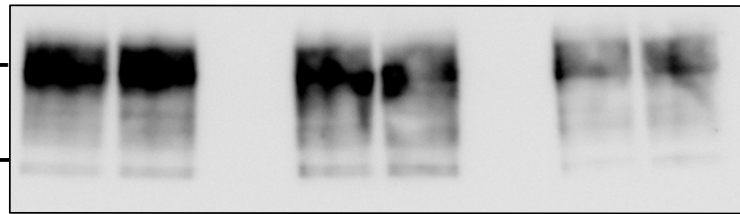

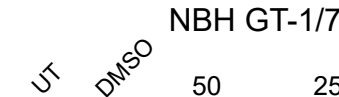

$250 \quad 1000$

PSA (nM)

\section{7}

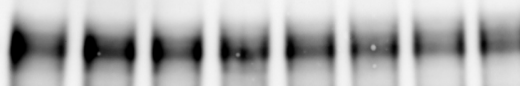

25

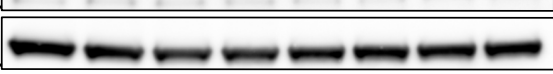

NBH hovS

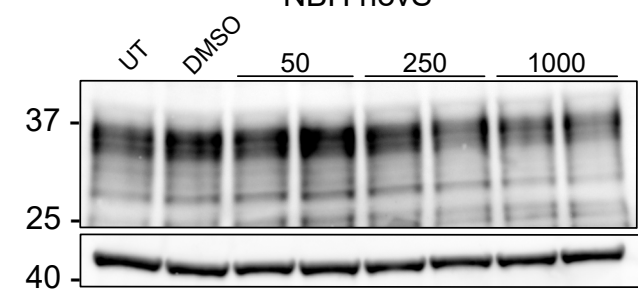

D

POM1

a-Actin

50

40

PSA (nM)

POM1

a-Actin
a-Actin

POM2

a-HNRNPK

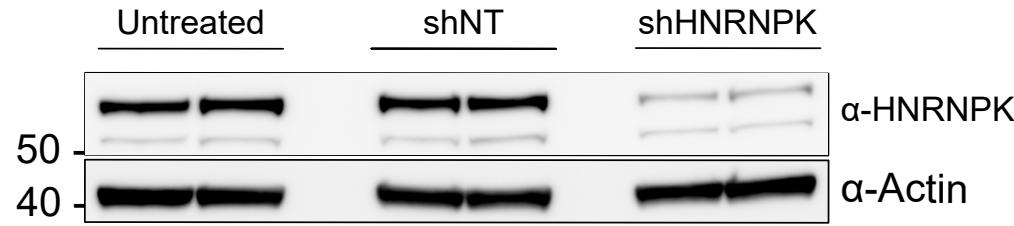

37
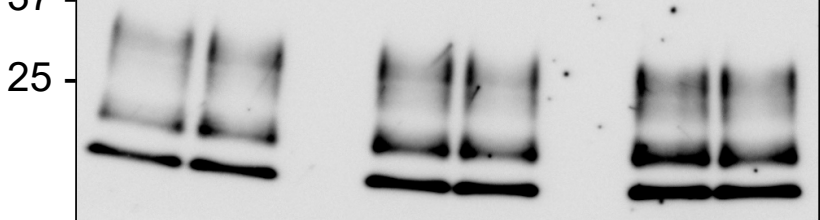

$+\mathrm{PK}$

POM1

PG127 hovS

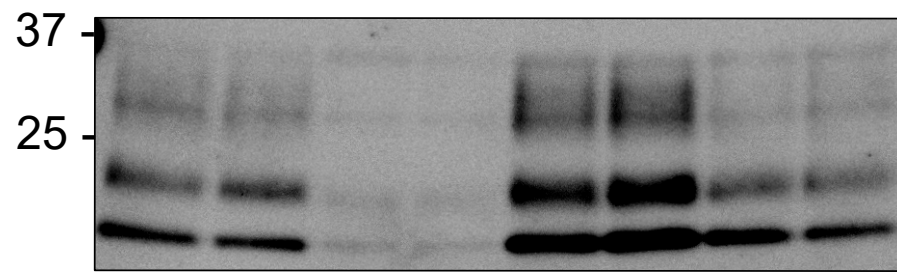

$+\mathrm{PK}$

POM1

Avar, Heinzer et al., Supplementary Fig. 4 